\title{
Green Synthesis of Silver Nanoparticles: A Review
}

\author{
Sista Kameswara Srikar ${ }^{1,2}$, Deen Dayal Giri1,3, Dan Bahadur Pal1, \\ Pradeep Kumar Mishra1, Siddh Nath Upadhyay ${ }^{*}$ \\ ${ }^{1}$ Department of Chemical Engineering \& Technology, Indian Institute of Technology (BHU) Varanasi, Varanasi, \\ Uttar Pradesh, India \\ ${ }^{2}$ Tata Steel, Jamshedpur, Jharkhand, India \\ ${ }^{3}$ Department of Botany, IFTM University, Moradabad, Uttar Pradesh, India \\ Email: "sista.sri@gmail.com,ddgiri1@gmail.com, danbahadur.chem@gmail.com,pkmishra.che@itbhu.ac.in, \\ upadhyaysnu@rediffmail.com, "snupadyay.che@itbhu.ac.in
}

Received 30 October 2015; accepted 26 February 2016; published 29 February 2016

Copyright (C) 2016 by authors and Scientific Research Publishing Inc.

This work is licensed under the Creative Commons Attribution International License (CC BY).

http://creativecommons.org/licenses/by/4.0/

(c) (i) Open Access

\begin{abstract}
The bio-molecules from various plant components and microbial species have been used as potential agents for the synthesis of silver nanoparticles (AgNPs). In spite of a wide range of bio-molecules assisting in the process, synthesizing stable and widely applicable AgNPs by many researchers still poses a considerable challenge to the researchers. The biological agents for synthesizing AgNPs cover compounds produced naturally in microbes and plants. More than 100 different biological sources for synthesizing AgNPs are reported in the past decade by various authors. Reaction parameters under which the AgNPs were being synthesized hold prominent impact on their size, shape and application. Available published information on AgNPs synthesis, effects of various parameters, characterization techniques, properties and their application are summarised and critically discussed in this review.
\end{abstract}

\section{Keywords}

AgNPs, Green Synthesis, Silver Nano, Plant Extract, Microbe

\section{Introduction}

Materials in the nano dimensions (1 - $100 \mathrm{~nm}$ ) have remarkable difference in the properties compared to the same material in the bulk. These differences lie in the physical and structural properties of atoms, molecules and

"Corresponding author. 
bulk materials of the element due to difference in physiochemical properties and surface to volume ratio [1]. With advancement in nanotechnology, a large number of nanomaterials are appearing with unique properties, opening spectrum of applications and research opportunities [2].

About 5000 years ago, many Greeks, Romans, Persians and Egyptians used silver in one form or other to store food products [3]. Use of silver ware during ancient period by various dynasties was common across the globe utensils for drinking and eating and storing various drinkable and eatable items probably due to the knowledge of antimicrobial action [4]. There are records regarding therapeutic application of silver in literature as earlier as 300 BC. In the Hindu religion, till date silver utensils are preferred for the "panchamrit" preparation using curd, Ocimum sanctum and other ingredients. The therapeutic potentials of various metals are mentioned in ancient Indian Aurvedic medicine book medicinal literature named "Charak Samhita" [5]. Until the discovery of antibiotics by Alexzander Flemming, silver was commonly used as antimicrobial agent.

In the recent past, silver nano particles (AgNps) have received enormous attention of the researchers due to their extraordinary defense against wide range of microorganisms and also due to the appearance of drug resistance against commonly used antibiotics [2]. The exceptional characteristics of AgNPs have made them applicable in various fields like biomedical [6], drug delivery [7], water treatment [8], agricultural etc. [9]. AgNps are applied in inks, adhesives, electronic devises, pastes etc. due to high conductivity [10]. AgNps have been synthesized by physio-chemical techniques such as chemical reduction [11], gamma ray radiation [12], micro emulsion [13], electrochemical method [14], laser ablation [15], autoclave [16], microwave [17] and photochemical reduction [18]. These methods have effective yield, but they are associated with the limitations like use of toxic chemicals and high operational cost and energy needs. Considering the drawbacks of physio-chemical methods, cost-effective and energy efficient new alternative for AgNP synthesis using microorganisms [2], plant extracts [19] and natural polymers [20] as reducing and capping agents are emerging very fast. The association of nanotechnology and green chemistry will unfold the range of biologically and cytologically compatible metallic nanoparticles [21] [22].

Over the past decade, few reviews focusing on green synthesis of AgNPs were published [23]-[27]. Most of these reviews focused on several plant and microbial sources for synthesis, several characterization techniques for analysis, certain tabular data representing source, shape and size and information regarding various applications. The present review, unlike the earlier ones, summarizes the synthesis procedure, parameters, characterizations, applications and predicted antibacterial mechanism in a systematic manner, focusing on various green routes for AgNPs synthesis.

\section{Green Synthesis}

The primary requirement of green synthesis of AgNPs is silver metal ion solution and a reducing biological agent. In most of the cases reducing agents or other constituents present in the cells acts as stabilizing and capping agents, so there is no need of adding capping and stabilizing agents from outside.

\subsection{Metal Ion Solution}

The $\mathrm{Ag}^{+}$ions are primary requirement for the synthesis of AgNPs which can be obtained from various water soluble salts of silver. However, the aqueous $\mathrm{AgNO}_{3}$ solution with $\mathrm{Ag}^{+}$ion concentration range between 0.1 - 10 $\mathrm{mm}$ (most commonly $1 \mathrm{~mm}$ ) has been used by the majority of researchers.

\subsection{Biological Reducing Agents}

The reducing agents are widely distributed in the biological systems. The AgNPs have been synthesized using different organisms belonging to four kingdom out of five kingdom of living organisms i.e. Monera (prokaryotic organisms without true nucleus) Protista (unicellular organisms with true nucleus), fungi (eukaryotic, saprophyte/parasite), plantae (eukaryotic, autotrophs) and animalia (eukaryotic, heterotrophs). Data are not available regarding use of animal materials for the synthesis of AgNP' till date to the best of our knowledge. Due to this limitation, green synthesis of AgNPs has been discussed under headings microorganisms, plants, and bio-polymers.

Green syntheses of AgNPs have been performed using plant extracts, microbial cell biomass or cell free growth medium and biopolymers. The plants used for AgNps synthesis range from algae to angiosperms; however, limited reports are available for lower plants and the most suitable choice are the angiosperm plants. Parts 
like leaf, bark, root, and stem have been used for the AgNP synthesis. The medicinally important plants like Boerhaavia diffusa [28], Tinospora cordifolia [29], Aloe vera [30], Terminalia chebula [31] Catharanthus roseus [32], Ocimum tenuiflorum [33], Azadirachta indica [34], Emblica officinalis [35], Cocos nucifera [36], common spices Piper nigrum [37]), Cinnamon zeylanicum [38]. Some exotic weeds like Parthenium hysterophorus [39] growing in uncontrolled manner due to lack of natural enemies and causing health problems have also been used for AgNP's synthesis. The other group includes alkaloids (Papaver somniferum) and essential oils (Mentha piperita) producing plants. All the plant extracts played dual role of potential reducing and stabilizing agents with an exception in few cases where external chemical agents like sodium-do-decyl sulphate were used for stabilization the AgNPs [40]). Metabolites, proteins [41] and chlorophyll [42] present in the plant extracts were found to be acting as capping agents for synthesized AgNPs.

The preferred solvent for extracting reducing agents from the plant is water in most of the cases however, there are few reports regarding the use of organic solvents like methanol [43]-[46], ethanol [47] [48] and ethyl acetate [49]. Some researchers pre-treated the plants materials in saline [39] or acetone [50] atmospheres before extraction. On the whole, even though the extracting solvents differed, the nanoparticle suspensions have made in aqueous medium only. Synthesis using plant extracts generate nanoparticles of well-defined shape, structure and morphology in compared to those obtained through the utilization of bark, tissue and whole plant [51].

The AgNPs synthesis by microbes is strenuous compared to the use of plant extracts and biopolymers as reducing and capping agents mainly due to the difficulty in growth, culture maintenance, and inoculums size standardization. Several fungal and bacterial species have been successfully used in the synthesis. The AgNPs synthesis mainly followed one of the two distinct routes, one utilizing extracellular materials secreted in the growth medium whereas the other utilizing microbial cell biomass directly. The microbes synthesize AgNP intracellularly as well as extracellularly. The Intracellular synthesis of AgNPs was observed by few researchers [52].

AgNPs synthesis supports better control on size and shape of AgNPs, due to easy down streaming and larger adaptability to nano systems. However, extracellular AgNP synthesis is been widely reported [53] [54]. One of the commonly used fungal genera for synthesizing AgNPs is Fusarium [53] [55]-[57]. No special capping agent was used in the work of many researchers for stabilizing synthesized AgNPs, except Perni et al. [58] and Shahverdi et al. [59] who used L-cystine and piperitone as stabilizing agents, respectively. Among the wide varieties off bio-polymers used for AgNP synthesis, almost all played the dual role of reducing and stabilizing agents with an exception of using starch as a capping agent [60].

\section{Separation of AgNPs}

Centrifugation technique is mostly used by researchers to obtain the pellet or powder form of synthesized silver nanoparticles. The AgNPs suspensions were also oven dried to obtain the product in powder form [44].

Some common characterizations of AgNPs include UV-Vis Spectra, SEM, TEM, FTIR, XRD and EDAX or EDX/EDS. DLS study is mostly used for AgNPs synthesized from bio-polymers rather than plant extracts and microorganisms. Zeta potential values indicate the stability of synthesized AgNPs. Thermo-Gravimetric Analysis (TGA) is used to find the effect of $\mathrm{AgNO}_{3}$ and L-cystine on the organic composition of AgNPs [58] to find out the amount of organic material in synthesized AgNPs [61] and predict the thermal stability of AgNPs [62]. Inductive Coupled Plasma (ICP) analysis was performed to analyze the concentration and conversion of AgNPs [19].

\section{Monitoring of AgNPs}

The appearance of yellow to slight brownish-yellow color in the colorless solution has been taken as indicative of AgNPs synthesis by almost all the researchers. The SPR peak of the synthesized AgNPs was witnessed in the range of 400 - $450 \mathrm{~nm}$, the significant range for AgNPs [63]. The UV-Vis spectral analyses have been used to analyze the dependency of $\mathrm{pH}$, metal ion concentration, extract content on the formation of AgNPs and reveal the size-stability of synthesized AgNPs by exhibiting red shift in the SPR peak with increase in size of nanoparticles and blue shift for decrease in size. The SEM morphological analysis in most of the studies revealed spherical AgNPs, whereas few authors reported irregular [64], triangular [65], hexagonal [66], isotropic [67], polyhedral [60], flake [68], flower [69], pentagonal [70], anisotropic [71] and rod like structures [72]. A pictorial representation of SEM/TEM images of AgNPs with different shapes is shown in Figure 1. Using XRD studies of almost all the researchers reported the formation of face centered cubic (FCC) crystalline structured AgNPs. 


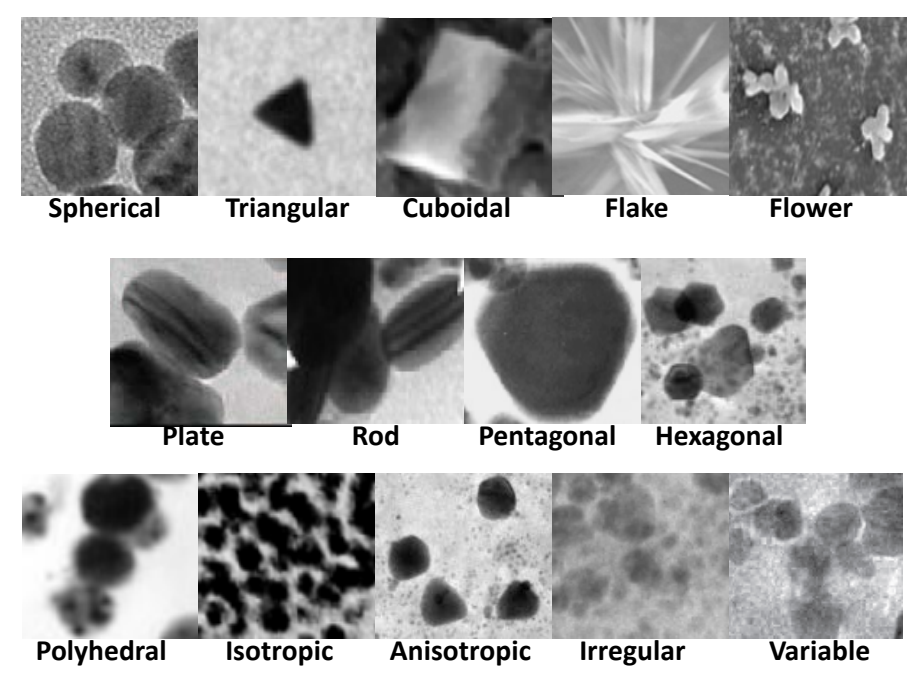

Figure 1.Various shapes of AgNPs synthesized (from various sources).

However, cubic and hexagonal structures were also reported in some cases. EDS or EDAX, for analyzing elemental composition in the nanomaterials, exhibited a characteristic optical absorption band peak around $3 \mathrm{KeV}$ with silver weight percentage ranging from $45 \%$ to $80 \%$. The reported stability of synthesized AgNPs has varied from 1 day to 1 year depending upon reducing agents and other operating conditions.

\section{Mechanism of AgNPs Synthesis}

The synthesis of AgNP by biological entities is due to the presence of large number of organic chemical like carbohydrate, fat, proteins, enzymes\& coenzymes, phenols flavanoids, terpenoids, alkaloids, gum, etc capable of donating electron for the reduction of $\mathrm{Ag}^{+}$ions to $\mathrm{Ag}^{0}$. The active ingredient responsible for reduction of $\mathrm{Ag}^{+}$ ions varies depending upon organism/extract used. For nano-transformation of AgNPs, electrons are supposed to be derived from dehydrogenation of acids (ascorbic acid) and alcohols (catechol) in hydrophytes, keto to enol conversions (cyperaquinone, dietchequinone, remirin) in mesophytes or both mechanisms in xerophytes plants [73]. The microbial cellular and extracellular oxidoreductase enzymes can perform similar reduction processes. A schematic diagram showing the silver ion reduction, agglomeration and stabilization to form a particle of nano size is shown in Figure 2.

\section{Factors Affecting AgNPs Synthesis}

The major physical and chemical parameters that affect the synthesis of AgNP are reaction temperature, metal ion concentration, extract contents, $\mathrm{pH}$ of the reaction mixture, duration of reaction and agitation. Parameters like metal ion concentration, extract composition and reaction period largely affect the size, shape and morphology of the AgNPs [62]. Most of the authors have reported suitability of basic medium for AgNPs synthesis due to better stability of the synthesized nanoparticles in basic medium [36] [44] [45] [74]. Some other advantages reported under basic $\mathrm{pH}$ are rapid growth rate [31] [75] [76] good yield and mono dispersity [77] and enhanced reduction process. Small and uniform sized nanoparticles were synthesized by increasing $\mathrm{pH}$ of the reaction mixture [60] [72] [77]-[79]. The nearly spherical AgNPs were converted to spherical AgNP by altering pH [22], However, very high $\mathrm{pH}(\mathrm{pH}>11)$ was associated with the drawback of formation of agglomerated and unstable AgNPs [80].

The Reaction conditions like time of stirring and reaction temperature are important parameters. Temperatures up to $100^{\circ} \mathrm{C}$ were used by many researchers for AgNP synthesis using bio-polymers and plant extracts, whereas the use of mesophilic microorganism restricted the reaction temperature to $40^{\circ} \mathrm{C}$. At higher temperatures the mesophilic microorganism dies due to the inactivation of their vital enzymes. The temperature increase $\left(30^{\circ} \mathrm{C}-90^{\circ} \mathrm{C}\right)$ resulted in increased rate of AgNPs synthesis [81] and also promoted the synthesis of smaller size AgNPs [82]. On the whole, most of workers have synthesized AgNPs at room temperature $\left(25^{\circ} \mathrm{C}\right.$ to $\left.37^{\circ} \mathrm{C}\right)$ range. A plot representing the size range of AgNPs synthesized in the room temperature range is elucidated in Figure 3. 


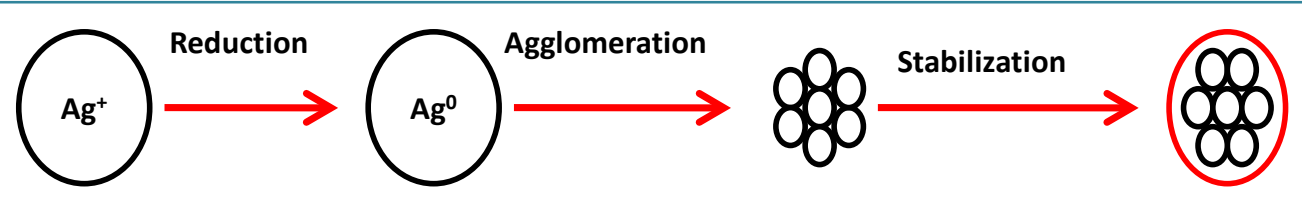

Figure 2.Synthesis mechanism of AgNPs.

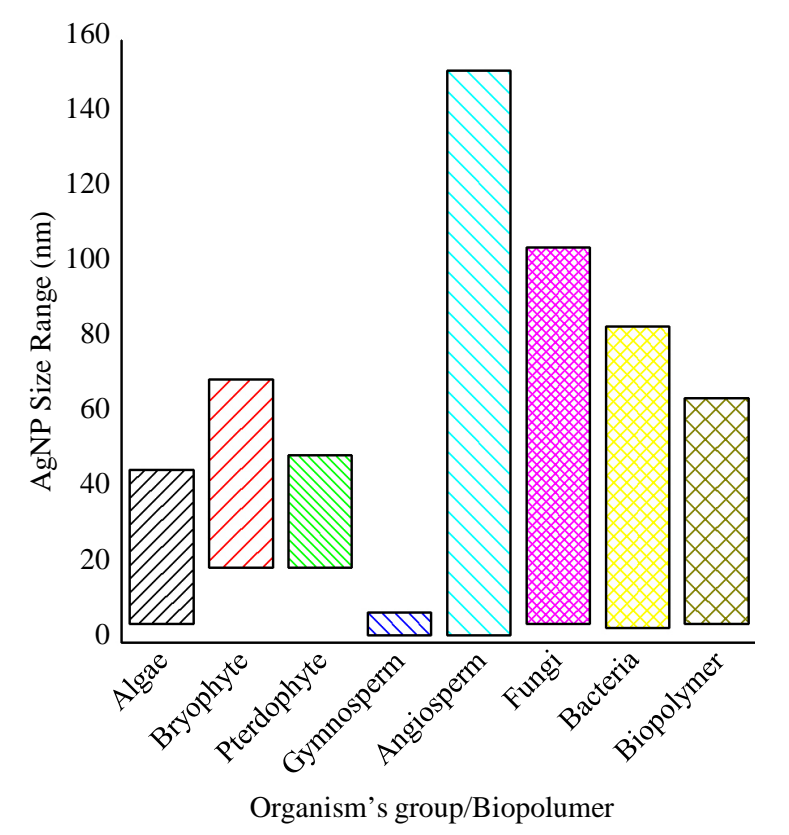

Figure 3. Size range of AgNPs synthesized at room temperature range (from various sources).

It has been found that the size range of AgNPs synthesized from algae, bryophytes, pteridophytes, gymnosperms and bio-polymer sources lie below $50 \mathrm{~nm}$ and that of AgNPs synthesized using from angiosperms, algae and bacterial sources ranged between $100 \mathrm{~nm}$ and more. The reaction mixture synthesizing AgNP using microorganisms and bio-polymers were continuously agitated to protect agglomeration compared to plant extracts without any suitable reason by the authors. Reaction mixture agitation achieved by applying external mechanical force might accelerate the formation of nanoparticles. Aging of the synthesized AgNP solution changed spherical nanoparticles into flower like structure [83] (Table 1).

\section{Applications of AgNPs}

The recent research results have shown that the AgNPs, due to their special characteristics, have immense potential for applications as anti-microbial, anti-parasitic and anti-fouling agents; as agents for site-specific medication, water purification systems, etc. The essential features of some of these applications are discussed in the following sections.

\subsection{Anti-Microbial Activity}

The AgNPs have been found to exhibit promising anti-micribial activity. Researchers have used several novel techniques to confirm and quantify the anti-micribial activity of AgNPs.

\subsubsection{Disc/Well Diffusion Methods}

The disc diffusion method, a most commonly used technique to access the antimicrobial activity of a liquid, has been employed by many researchers to confirm antimicrobial action of the AgNPs solution. In this method, uniform sized disc of adsorbent material are dipped in the increasing concentration of AgNP and placed over surface of the targeted microbe inoculated on the nutrient medium plates. An inhibition zone formation around the disc reflects antimicrobial action of the nanomaterials [72] [94] [95] [101] [104] [111] and well diffusion [29] 
Table 1. Summary of the work related AgNPs synthesis using green route.

\begin{tabular}{|c|c|c|c|c|c|c|}
\hline $\begin{array}{l}\text { S. } \\
\text { No. }\end{array}$ & Author & Reducing Agent & Operating Conditions & Characterization & $\begin{array}{l}\text { Particle } \\
\text { Characteristics }\end{array}$ & Remarks \\
\hline \multicolumn{7}{|c|}{ Algae } \\
\hline 1 & $\begin{array}{l}\text { Kathiraven et al. } \\
\text { (2014) [84] }\end{array}$ & $\begin{array}{l}\text { Filtered aqueous extract of } \\
\text { Caulerpa racemosa } \\
\text { marine algae }\end{array}$ & $\begin{array}{l}\mathrm{AgNO}_{3} \text { concentration-1 } 1 \mathrm{mM} \text {, } \\
\text { Reaction period-3 } 3 \mathrm{hr} \text {, } \\
\text { Reaction temp-room temp. } \\
\text { Extract: } 10 \mathrm{ml} / 90 \mathrm{ml} \\
\left(\mathrm{AgNO}_{3}\right) \text {, } \\
\text { Motion: static }\end{array}$ & $\begin{array}{l}\text { UV-Vis } \\
\text { FTIR } \\
\text { TEM } \\
\text { XRD }\end{array}$ & $\begin{array}{l}\text { Size-5 - } 25 \mathrm{~nm} \\
\text { Shape-sph, tri. } \\
\text { Structure-FCC }\end{array}$ & $\begin{array}{l}\text { Antibacterial action against } P . \\
\text { mirabilis and S. aureus }\end{array}$ \\
\hline 2 & $\begin{array}{l}\text { Rajesh et al. (2012) } \\
\text { [49] }\end{array}$ & $\begin{array}{l}\text { Ethyl acetate } \\
\text { extract of Ulva fasciata }\end{array}$ & $\begin{array}{l}1 \mathrm{mM}, 2 \mathrm{~min} \text {, room temp. } \\
3 \mathrm{ml} / 100 \mathrm{ml} \text {, } \\
\text { Static }\end{array}$ & $\begin{array}{l}\text { UV-Vis } \\
\text { FTIR } \\
\text { SEM } \\
\text { XRD } \\
\text { EDX }\end{array}$ & $\begin{array}{l}\text { Size-28 - } 41 \mathrm{~nm} \\
\text { Shape-sph } \\
\text { Structure-cryst } \\
\text { Nature-PD }\end{array}$ & $\begin{array}{l}\text { Antibacterial action against } X \text {. } \\
\text { campestrispv malvacearum } \\
\text { pathogen }\end{array}$ \\
\hline 3 & $\begin{array}{l}\text { Vivek et al. (2011) } \\
\text { [85] }\end{array}$ & $\begin{array}{l}\text { Aqueous filtrate of } \\
\text { Gelidiella acerosa }\end{array}$ & $\begin{array}{l}1 \mathrm{mM}, \text { room temp, } \\
10 \mathrm{ml} / 90 \mathrm{ml} \text {, } \\
\text { Agitated }\end{array}$ & $\begin{array}{l}\text { UV-Vis } \\
\text { FTIR } \\
\text { SEM } \\
\text { TEM } \\
\text { XRD }\end{array}$ & $\begin{array}{l}\text { Size- } 22 \mathrm{~nm} \\
\text { Shape-sph. } \\
\text { Structure-FCC } \\
\text { Nature-PD }\end{array}$ & $\begin{array}{l}\text { Antifungal against Mucor } \\
\text { inicus and Trichoderma reesei }\end{array}$ \\
\hline 4 & $\begin{array}{l}\text { Govindaraju et al. } \\
\text { (2009) [86] }\end{array}$ & $\begin{array}{l}\text { Aqueous filtrate of } \\
\text { Sargassum wightii }\end{array}$ & $\begin{array}{l}1 \mathrm{mM}, 1 \mathrm{hr} \text {, room temp, } \\
10 \mathrm{ml} / 90 \mathrm{ml} \text {, } \\
\text { Static }\end{array}$ & $\begin{array}{l}\text { UV-Vis } \\
\text { FTIR } \\
\text { TEM } \\
\text { XRD }\end{array}$ & $\begin{array}{l}\text { Size-8 - } 27 \mathrm{~nm} \\
\text { Shape-sph/variable } \\
\text { Structure-cryst }\end{array}$ & $\begin{array}{l}\text { Antibacterial against } S \text {. } \\
\text { aureus, B. rhizoids, E. coli } \\
\text { and P. aeruginosa }\end{array}$ \\
\hline \multicolumn{7}{|c|}{ Bryophyte } \\
\hline 5 & $\begin{array}{l}\text { Kulkarni et al. } \\
\text { (2012) [47] }\end{array}$ & Ethanol filtrate of Riccia & $\begin{array}{l}1 \mathrm{mM}, 25^{\circ} \mathrm{C} \text {, dark, } \\
5 \mathrm{ml} / 1 \mathrm{ml}, \\
\text { Agitated }\end{array}$ & $\begin{array}{l}\text { UV-Vis } \\
\text { SEM } \\
\text { EDS }\end{array}$ & Shape—cub/triang & $\begin{array}{l}\text { Antibacterial against } p \text {. } \\
\text { aeruginosa }\end{array}$ \\
\hline 6 & $\begin{array}{l}\text { Kulkarni et al. } \\
\text { (2012) [47] }\end{array}$ & $\begin{array}{l}\text { Ethanol filtrate of } \\
\text { Anthoceras }\end{array}$ & $\begin{array}{l}0.5 \mathrm{mM}, 10 \mathrm{~min} \text {, room temp. } \\
5 \mathrm{ml} / 1 \mathrm{ml} \text {, Static }\end{array}$ & $\begin{array}{l}\text { UV-Vis } \\
\text { SEM } \\
\text { EDS }\end{array}$ & $\begin{array}{l}\text { Size-20 - } 50 \mathrm{~nm} \\
\text { Shape—cub/triang }\end{array}$ & $\begin{array}{l}\text { Antibacterial activity after } \\
\text { incorporation into gauze cloth }\end{array}$ \\
\hline 7 & $\begin{array}{l}\text { Srivastava et al. } \\
\text { (2011) [87] }\end{array}$ & $\begin{array}{l}\text { Aqueous and } \\
\text { ethanol filtrate of } \\
\text { Fissidens minutes }\end{array}$ & $\begin{array}{l}0.5 \mathrm{mM}, 1 \mathrm{hr} \text {, room temp. } \\
10 \mathrm{ml} / 1 \mathrm{ml} \text {, } \\
\text { Shaken }\end{array}$ & $\begin{array}{l}\text { UV-Vis } \\
\text { SEM } \\
\text { EDS }\end{array}$ & Shape—nearly sph & $\begin{array}{l}\text { Antibacterial action against } E \text {. } \\
\text { coli, B. cereus, } K \text {. } \\
\text { pneumoniae, P. aeruginosa }\end{array}$ \\
\hline 8 & $\begin{array}{l}\text { Kulkarni et al. } \\
\text { (2011) [88] }\end{array}$ & $\begin{array}{l}\text { Aqueous filtrate of } \\
\text { Anthoceras }\end{array}$ & $\begin{array}{l}1 \mathrm{mM}, 25^{\circ} \mathrm{C} \text {, dark, } \\
5 \mathrm{ml} / 1 \mathrm{ml} \\
\text { Agitated }\end{array}$ & $\begin{array}{l}\text { UV-Vis } \\
\text { SEM } \\
\text { EDS }\end{array}$ & $\begin{array}{l}\text { Size-20 - } 50 \mathrm{~nm} \\
\text { Shape—cub/triang }\end{array}$ & $\begin{array}{l}\text { Antibacterial action against } E \text {. } \\
\text { coli, B. subtilis, K. } \\
\text { pneumoniae, P. aeruginosa }\end{array}$ \\
\hline \multicolumn{7}{|c|}{ Pteridophyte } \\
\hline 9 & $\begin{array}{l}\text { John De Britto et al. } \\
\text { (2014) [89] }\end{array}$ & $\begin{array}{l}\text { Aqueous filtrate of Pteris } \\
\text { argyreae, Pteris confuse } \\
\text { and Pteris blaurita }\end{array}$ & $\begin{array}{l}1 \mathrm{mM}, 28 \mathrm{hr} \text {, room temp. } \\
5 \mathrm{ml} / 100 \mathrm{ml} \text {, } \\
\text { Static, Centrifugation: } 25 \mathrm{~min} \\
\text { at } 10000 \mathrm{rpm} .\end{array}$ & & & $\begin{array}{l}\text { Antibacterial action against } \\
\text { Shigella boydii, Shigella } \\
\text { dysenteriae, S. aureus, } \\
\text { Klebsiella vulgaris and } \\
\text { Salmonalla typhi }\end{array}$ \\
\hline 10 & $\begin{array}{l}\text { Bhor et al. (2014) } \\
\text { [90] }\end{array}$ & $\begin{array}{l}\text { Aqueous filtrate of } \\
\text { Nephrolepis sexaltata L. } \\
\text { fern }\end{array}$ & $\begin{array}{l}1 \mathrm{mM}, 4 \mathrm{~h}, \\
10 \mathrm{ml} / 90 \mathrm{ml}\end{array}$ & $\begin{array}{l}\text { UV-Vis } \\
\text { SEM } \\
\text { XRD }\end{array}$ & $\begin{array}{l}\text { Size—avg } 24.76 \mathrm{~nm} \\
\text { Shape—sph. } \\
\text { Structure-FCC }\end{array}$ & $\begin{array}{l}\text { Antibacterial against many } \\
\text { human and plant pathogens }\end{array}$ \\
\hline 11 & $\begin{array}{l}\text { Sant et al. (2013) } \\
\text { [71] }\end{array}$ & $\begin{array}{l}\text { Aqueous filtrate of } \\
\text { Adiantum philippense } \mathrm{L} \text {. }\end{array}$ & $\begin{array}{l}1-10 \mathrm{mM}, 30^{\circ} \mathrm{C} \\
\text { Extract: } \mathrm{AgNO}_{3} \\
\text { Ratio-1: } 10 ; 1: 100 ; 1: 1000 \text {, } \\
\text { Agitated }\end{array}$ & $\begin{array}{l}\text { UV-Vis } \\
\text { FTIR } \\
\text { EDS } \\
\text { TEM } \\
\text { DLS } \\
\text { XRD }\end{array}$ & $\begin{array}{l}\text { Size-10 - } 18 \mathrm{~nm} \\
\text { Shape-anisotropic } \\
\text { Structure-FCC } \\
\text { Nature-MD }\end{array}$ & $\begin{array}{l}\text { AgNps from } \\
\text { medicinally important plants } \\
\text { opens spectrum of medical } \\
\text { applications. }\end{array}$ \\
\hline 12 & $\begin{array}{l}\text { Nalwade et al. } \\
\text { (2013) [91] }\end{array}$ & $\begin{array}{l}\text { Aqueous filtrate of } \\
\text { Cheilanthes } \\
\text { forinosa Forsk leaf }\end{array}$ & $\begin{array}{l}1 \mathrm{mM}, 4 \mathrm{hr} \text {, room temp. } \\
10 \mathrm{ml} / 90 \mathrm{ml}\end{array}$ & $\begin{array}{l}\text { UV-Vis } \\
\text { SEM } \\
\text { XRD }\end{array}$ & $\begin{array}{l}\text { Size- } 26.58 \mathrm{~nm} \\
\text { Shape-sph. } \\
\text { Structure-FCC }\end{array}$ & $\begin{array}{l}\text { Antibacterial action against } S \text {. } \\
\text { aureus and Proteus morgani }\end{array}$ \\
\hline 13 & $\begin{array}{l}\text { Kang et al. (2008) } \\
\text { [92] }\end{array}$ & $\begin{array}{l}\text { Aqueous filtrate of } \\
\text { Pteridophyta }\end{array}$ & $\begin{array}{l}1 \mathrm{mM}, 12 \mathrm{hr} \text {, room temp. } \\
10 \mathrm{ml} / 100 \mathrm{ml} \text {, Static }\end{array}$ & $\begin{array}{l}\text { UV-Vis } \\
\text { TEM } \\
\text { EDX }\end{array}$ & $\begin{array}{l}\text { Size-20 - } 30 \mathrm{~nm} \\
\text { Shape-sph. }\end{array}$ & $\begin{array}{l}\text { AgNps are stable for } 12 \\
\text { months. }\end{array}$ \\
\hline \multicolumn{7}{|c|}{ Gymnosperms } \\
\hline 14 & $\begin{array}{l}\text { Jha and Prasad. } \\
\text { (2010) [93] }\end{array}$ & $\begin{array}{l}\text { Filtered } \\
\text { aqueous-ethanol extract of } \\
\text { Cycas leaf }\end{array}$ & $\begin{array}{l}0.25 \mathrm{M}, 10 \mathrm{~min} \text {, room temp. } \\
80 \mathrm{ml} / 20 \mathrm{ml} \text {, } \\
\text { Static }\end{array}$ & $\begin{array}{l}\text { UV-Vis } \\
\text { TEM } \\
\text { XRD }\end{array}$ & $\begin{array}{l}\text { Size-2 - } 6 \mathrm{~nm} \\
\text { Shape-sph. } \\
\text { Structure-FCC }\end{array}$ & $\begin{array}{l}\text { The extraction of cycas leaf is } \\
\text { done in } 50 \% \text { EtOH as solvent. }\end{array}$ \\
\hline 15 & $\begin{array}{l}\text { Song and Kim. } \\
\text { (2009) [19] }\end{array}$ & $\begin{array}{l}\text { Decanted aqueous extract } \\
\text { of Pinus desiflora and } \\
\text { Ginko biloba leaf }\end{array}$ & $\begin{array}{l}0.1-2 \mathrm{~mm}, 30 \mathrm{~min}, \\
25^{\circ} \mathrm{C}-95^{\circ} \mathrm{C} \\
10 \mathrm{ml} / 190 \mathrm{ml} \\
\text { Static, } 20 \mathrm{~min}(15 \mathrm{k} \mathrm{rpm})\end{array}$ & $\begin{array}{l}\text { UV-Vis } \\
\text { SEM } \\
\text { TEM } \\
\text { EDS } \\
\text { ICP }\end{array}$ & $\begin{array}{l}\text { Size-15-500 nm } \\
\text { Shape—sph. } \\
\text { Structure—cryst }\end{array}$ & $\begin{array}{l}\text { AgNps were stable for } 4 \\
\text { weeks. }\end{array}$ \\
\hline \multicolumn{7}{|c|}{ Angiosperms } \\
\hline 16 & $\begin{array}{l}\text { Ashokkumar et al. } \\
\text { (2015) [94] }\end{array}$ & $\begin{array}{l}\text { Filtered aqueous extract of } \\
\text { Abutilon indicum leaf }\end{array}$ & $\begin{array}{l}10 \mathrm{~mm}, 15 \mathrm{~min} \text {, room temp. } \\
2 \text { to } 3.5 \mathrm{ml} / 30 \mathrm{ml} \text {, Static }\end{array}$ & $\begin{array}{l}\text { UV-Vis } \\
\text { FTIR } \\
\text { FE-SEM } \\
\text { TEM } \\
\text { XRD } \\
\text { FS }\end{array}$ & $\begin{array}{l}\text { Size-7 - } 17 \mathrm{~nm} \\
\text { Shape-sph. } \\
\text { Structure-FCC }\end{array}$ & $\begin{array}{l}\text { Antimicrobial action against } \\
\text { S. typhi, E. coli, S. aureus, } \\
\text { B. substilus }\end{array}$ \\
\hline 17 & $\begin{array}{l}\text { Sadeghi et al. } \\
\text { (2015) [45] }\end{array}$ & $\begin{array}{l}\text { Filtered aqueous-methanol } \\
\text { extract of Pistacia } \\
\text { atlantica seed powder. }\end{array}$ & $\begin{array}{l}1 \mathrm{mM}, 35 \mathrm{~min} \text {, room temp. } \\
1 \mathrm{ml} / 10 \mathrm{ml} \text {, } \\
\text { Shaken, } 15 \mathrm{~min} \text { at } 10 \mathrm{k} \mathrm{rpm}\end{array}$ & $\begin{array}{l}\text { UV-Vis } \\
\text { FTIR } \\
\text { SEM } \\
\text { TEM } \\
\text { XRD } \\
\text { EDAX } \\
\text { ZP }\end{array}$ & $\begin{array}{l}\text { Size-10 - } 50 \mathrm{~nm} \\
\text { Shape-sph. } \\
\text { Structure-FCC }\end{array}$ & $\begin{array}{l}\text { Stability: } 7-11 \mathrm{pH} \text { range. } \\
\text { Antibacterial affect against } S \text {. } \\
\text { aureus. }\end{array}$ \\
\hline
\end{tabular}




\section{Continued}

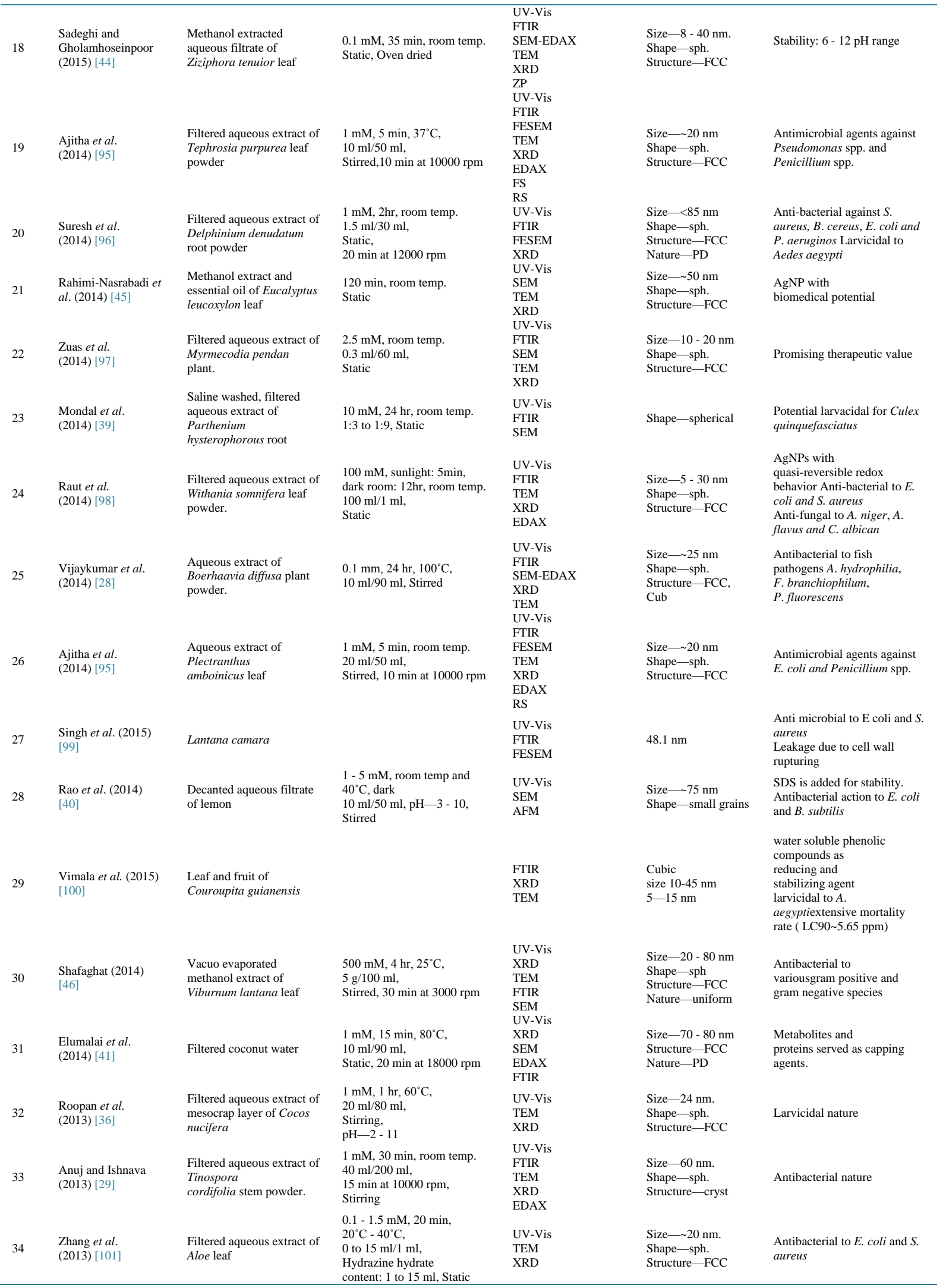




\section{Continued}

\begin{tabular}{|c|c|c|c|c|c|c|}
\hline 35 & $\begin{array}{l}\text { Yang et al. } \\
\text { (2013) [74] }\end{array}$ & $\begin{array}{l}\text { Filtered aqueous extract of } \\
\text { Mangifera indica linn peel }\end{array}$ & $\begin{array}{l}0.5 \text { to } 4 \mathrm{mM}, 15 \text { to } 90 \mathrm{~min} \text {, } \\
25 \text { to } 100^{\circ} \mathrm{C} \text {, } \\
0.1 \text { to } 3 \mathrm{ml} / 27 \mathrm{ml} \text {, } \\
\text { pH: } 2-11 . \\
\text { Static }\end{array}$ & $\begin{array}{l}\text { UV-Vis } \\
\text { TEM } \\
\text { XRD }\end{array}$ & $\begin{array}{l}\text { Size-7 - } 27 \mathrm{~nm} \\
\text { Shape-sph. } \\
\text { Structure-FCC }\end{array}$ & $\begin{array}{l}\text { Stable for } 3 \text { months, } \\
\text { AgNPs loaded on fabrics } \\
\text { exhibited antimicrobial } \\
\text { property. }\end{array}$ \\
\hline 36 & $\begin{array}{l}\text { Jagtap and Bapat. } \\
\text { (2013) [64] }\end{array}$ & $\begin{array}{l}\text { Filtered aqueous extract of } \\
\text { Artocarpus } \\
\text { heterophyllus lam. Seed } \\
\text { powder }\end{array}$ & $\begin{array}{l}2 \text { to } 10 \mathrm{mM}, 5 \mathrm{~min}, 121^{\circ} \mathrm{C} \text {, } \\
15 \mathrm{psi} \text {. } \\
2 \text { to } 10 \mathrm{w} / \mathrm{v} \%, 1: 4, \\
\text { Static, } 15 \mathrm{~min} \text { at } 10000 \mathrm{rpm}\end{array}$ & $\begin{array}{l}\text { UV-Vis } \\
\text { FTIR } \\
\text { SEM-EDAX } \\
\text { TEM }\end{array}$ & $\begin{array}{l}\text { Size- }-3-25 \mathrm{~nm} \\
\text { Shape-irregular }\end{array}$ & $\begin{array}{l}\text { Anti-bacterial to B. cereus, } B \text {. } \\
\text { subtilis, } S \text {. aureus and } P \text {. } \\
\text { aeruginosa. } \\
\text { AgNP-lectin hybrid has } \\
\text { promising use in glycol } \\
\text { nanosensors for disease } \\
\text { diagnosis. }\end{array}$ \\
\hline 37 & $\begin{array}{l}\text { Khalil et al. } \\
\text { (2013) [75] }\end{array}$ & $\begin{array}{l}\text { Filtered aqueous extract of } \\
\text { olive leaf }\end{array}$ & $\begin{array}{l}1 \mathrm{mM}, 2 \mathrm{~min}, 30^{\circ} \mathrm{C} \text { to } 90^{\circ} \mathrm{C} \text {, } \\
0.5 \text { to } 5 \mathrm{ml} / 10 \mathrm{ml} \text {, } \\
\text { pH: } 2-11 \text {, Stirred }\end{array}$ & $\begin{array}{l}\text { UV-Vis } \\
\text { FTIR } \\
\text { SEM } \\
\text { TEM } \\
\text { XRD } \\
\text { TGA }\end{array}$ & $\begin{array}{l}\text { Size-20 - } 25 \mathrm{~nm} \\
\text { Shape-sph. } \\
\text { Structure-FCC }\end{array}$ & $\begin{array}{l}\text { Stability: } 1 \text { week, } \\
\text { AgNPs inhibited growth of } E \text {. } \\
\text { coli, S. aureus and } P \text {. } \\
\text { aeruginosa }\end{array}$ \\
\hline 38 & $\begin{array}{l}\text { Karuppiah and } \\
\text { Rajmohan } \\
\text { (2013) [102] }\end{array}$ & $\begin{array}{l}\text { Filtered aqueous extract of } \\
\text { Lxora coccinea } L \text {. leaf }\end{array}$ & $\begin{array}{l}1 \mathrm{mM} \text {, dark and room temp. } \\
0.5 \mathrm{ml} / 10 \mathrm{ml} \text {, } \\
15 \mathrm{~min} \text { at } 10000 \mathrm{rpm} \text {, } \\
\text { Static }\end{array}$ & $\begin{array}{l}\text { UV-Vis } \\
\text { FTIR. } \\
\text { FE-SEM } \\
\text { XRD }\end{array}$ & $\begin{array}{l}\text { Size-13 - } 57 \mathrm{~nm} \\
\text { Shape-sph. } \\
\text { Structure-FCC }\end{array}$ & \\
\hline 39 & $\begin{array}{l}\text { Logeswari et al. } \\
(2013)[103]\end{array}$ & $\begin{array}{l}\text { Filtered ethanolic extracts } \\
\text { of Solanum tricobactum, } \\
\text { syzygium cumini, centella } \\
\text { asiatica and citrus } \\
\text { sinensis plant powders }\end{array}$ & $\begin{array}{l}1 \mathrm{mM}, 24-48 \mathrm{hr}, 37^{\circ} \mathrm{C} \text {, } \\
10 \mathrm{ml} / 5 \mathrm{ml} \text {, } \\
\text { Additive: ammonium } \\
\text { solution= } 2.5 \mathrm{ml} \text {, } \\
\text { agitated }\end{array}$ & $\begin{array}{l}\text { UV-Vis } \\
\text { FTIR } \\
\text { XRD } \\
\text { AFM }\end{array}$ & $\begin{array}{l}\text { Size-41 - } 53 \mathrm{~nm} \text {. } \\
\text { Shape—irregular } \\
\text { Structure-FCC }\end{array}$ & $\begin{array}{l}\text { Antibacterial against } \\
\text { pathogenic } P \text {. } \\
\text { aeruginosa }\end{array}$ \\
\hline 40 & $\begin{array}{l}\text { Geetha lakshmi and } \\
\text { Sarada } \\
\text { (2013) [104] }\end{array}$ & $\begin{array}{l}\text { Sponin extracted from } \\
\text { Trianthema decendra L. }\end{array}$ & $\begin{array}{l}1 \mathrm{mM} \text {, dark and } \\
\text { incubated, } \\
1 \mathrm{ml} / 5 \mathrm{ml} \text {, } \\
\text { Static, } 15 \mathrm{~min} \text { at } 10000 \mathrm{rpm}\end{array}$ & $\begin{array}{l}\text { UV-Vis } \\
\text { FTIR } \\
\text { FE-SEM } \\
\text { EDAX }\end{array}$ & $\begin{array}{l}\text { Size-17.9 - } 59.6 \\
\text { nm. } \\
\text { Shape—sph. }\end{array}$ & $\begin{array}{l}\text { Antibacterial to } P \text {. } \\
\text { aeruginosa, E. } \\
\text { faecalis, S. typhi, } K \text {. } \\
\text { pneumonia, E. coli and C. } \\
\text { albicans }\end{array}$ \\
\hline 41 & $\begin{array}{l}\text { Yasin et al. (2013) } \\
\text { [105] }\end{array}$ & $\begin{array}{l}\text { Filtered aqueous extract of } \\
\text { Bamboo leaf }\end{array}$ & $\begin{array}{l}3 \mathrm{mM}, 65^{\circ} \mathrm{C} \\
5 \mathrm{ml} / 5 \mathrm{ml} \\
\text { Stirring }\end{array}$ & $\begin{array}{l}\text { UV-Vis } \\
\text { TEM } \\
\text { XRD } \\
\text { EDX }\end{array}$ & $\begin{array}{l}\text { Size-13 } \pm 3.5 \mathrm{~nm} \\
\text { Shape-nearly sph. } \\
\text { Structure-cryst }\end{array}$ & $\begin{array}{l}\text { Antibacterial to E. coli and } S \text {. } \\
\text { aureus }\end{array}$ \\
\hline 42 & $\begin{array}{l}\text { Rodriguez-Leon et } \\
\text { al. (2013) [106] }\end{array}$ & $\begin{array}{l}\text { Ethanol/aqueous extract of } \\
\text { Rumex hymenosepalus } \\
\text { root }\end{array}$ & $\begin{array}{l}2.5 \text { - } 15 \mathrm{mM}, 24 \text { - } 96 \mathrm{hr} \text {, } \\
\text { room temp. } \\
5 \% \mathrm{v} / \mathrm{v} \text {, Static }\end{array}$ & $\begin{array}{l}\text { UV-Vis } \\
\text { TEM } \\
\text { EDS }\end{array}$ & $\begin{array}{l}\text { Size }-2-40 \mathrm{~nm} \\
\text { cub and hex } \\
\text { Structure-FCC }\end{array}$ & $\begin{array}{l}\text { AgNPs are } \\
\text { synthesized in ethanol } \\
\text { medium. }\end{array}$ \\
\hline 43 & $\begin{array}{l}\text { Rajathi and Sridhar } \\
\text { (2013) [107] }\end{array}$ & $\begin{array}{l}\text { Decanted aqueous filtrate } \\
\text { of Wrightia tinctoria leaf }\end{array}$ & $\begin{array}{l}1 \mathrm{mM}, 2 \mathrm{hr} \text {, room temp. } \\
0.5 \mathrm{ml} / 10 \mathrm{ml} \text {, Static, } \\
10 \mathrm{~min} \text { at } 10000 \mathrm{rpm}\end{array}$ & $\begin{array}{l}\text { UV-Vis } \\
\text { FTIR } \\
\text { XRD }\end{array}$ & $\begin{array}{l}\text { Size }-5-20.5 \mathrm{~nm} \\
\text { Structure-cryst }\end{array}$ & $\begin{array}{l}\text { Antibacterial to } S \text {. aureus, } V \text {. } \\
\text { cholerae, M. luteus and } K \text {. } \\
\text { pneumonia }\end{array}$ \\
\hline 44 & $\begin{array}{l}\text { Kannan et al. } \\
\text { (2013) [108] }\end{array}$ & $\begin{array}{l}\text { Filtered aqueous extract of } \\
\text { codium captium sea weed } \\
\text { powder. }\end{array}$ & $\begin{array}{l}1 \mathrm{mM}, 48 \mathrm{hr} \text {, room temp, } \\
\text { dark, } \\
12 \mathrm{ml} / 1 \mathrm{ml}, \\
\text { Static, } \\
20 \text { min at } 12000 \mathrm{rpm}\end{array}$ & $\begin{array}{l}\text { UV-Vis } \\
\text { FTIR } \\
\text { SEM-EDAX } \\
\text { TEM }\end{array}$ & $\begin{array}{l}\text { Size-3 - } 44 \mathrm{~nm} \\
\text { Nature-nano- } \\
\text { clusters }\end{array}$ & $\begin{array}{l}\text { Fresh extract was more potent } \\
\text { for AgNP synthesis. }\end{array}$ \\
\hline 45 & $\begin{array}{l}\text { Natarajan et al. } \\
\text { (2013) [109] }\end{array}$ & $\begin{array}{l}\text { Powdered } \\
\text { Elaeagnus indica leaves }\end{array}$ & $\begin{array}{l}0.5-2 \mathrm{mM}, 20-60 \mathrm{~min}, \\
40^{\circ} \mathrm{C}-100^{\circ} \mathrm{C}, 10 \mathrm{~g} / 3 \mathrm{ml}, \\
\text { Static, } \\
10 \mathrm{~min} \text { at } 12000 \mathrm{rpm}\end{array}$ & $\begin{array}{l}\text { UV-Vis } \\
\text { FTIR } \\
\text { TEM } \\
\text { DLS }\end{array}$ & $\begin{array}{l}\text { Size—avg } 30 \mathrm{~nm} \\
\text { Shape-sph. } \\
\text { Nature-MD }\end{array}$ & $\begin{array}{l}\text { Antimicrobial against E.coli, } \\
\text { P. putida, B. subtilis, S. } \\
\text { aureus, } \\
\text { A. flavus and } \\
\text { F. oxysporum }\end{array}$ \\
\hline 46 & $\begin{array}{l}\text { Kirubaharan et al. } \\
\text { (2012) [110] }\end{array}$ & $\begin{array}{l}\text { Filtered aqueous extract of } \\
\text { Azadirchata } \\
\text { indica(neem) leaves }\end{array}$ & $\begin{array}{l}1 \mathrm{mM}, 90 \mathrm{~min} \text {, room to } 90^{\circ} \mathrm{C} \text {, } \\
1.25 \mathrm{ml} / 50 \mathrm{ml}, \mathrm{pH}: 6-8 . \\
\text { Stirred }\end{array}$ & $\begin{array}{l}\text { UV-Vis } \\
\text { TEM } \\
\text { XRD }\end{array}$ & $\begin{array}{l}\text { Size-15 - } 20 \mathrm{~nm} \\
\text { Shape-sph. } \\
\text { Structure-FCC } \\
\text { Nature-MD, PD }\end{array}$ & $\begin{array}{l}\text { Stability: } 4 \text { months, } \\
\text { Heavy metal ion } \\
\text { sensors in aqueous media }\end{array}$ \\
\hline 47 & $\begin{array}{l}\text { Satishkumar et al. } \\
\text { (2012) [72] }\end{array}$ & $\begin{array}{l}\text { Filtered aqueous extract of } \\
\text { Morinda citifolia L. leaf } \\
\text { powder }\end{array}$ & $\begin{array}{l}1 \mathrm{mM}, 0-60 \mathrm{~min}, \\
37^{\circ} \mathrm{C}-100^{\circ} \mathrm{C} \\
5 \mathrm{ml} / 95 \mathrm{ml}, \\
5 \mathrm{~min} \text { at } 5000 \mathrm{rpm}, \\
\text { Static }\end{array}$ & $\begin{array}{l}\text { UV-Vis } \\
\text { FTIR } \\
\text { SEM } \\
\text { HR-TEM }\end{array}$ & $\begin{array}{l}\text { Size-10 - } 60 \mathrm{~nm} \\
\text { Shape-sph. } \\
\text { Structure-FCC }\end{array}$ & $\begin{array}{l}\text { Stability } 1 \text { month, } \\
\text { Inhibitory to human } \\
\text { pathogens like E. coli, } P \text {. } \\
\text { aeroginosa, K. pneumoniae, } \\
\text { B. cereus, Enterococci spp. } \\
\text { and Enterobacter } \\
\text { aerogenes }\end{array}$ \\
\hline 48 & $\begin{array}{l}\text { Edison and } \\
\text { Sethuraman. } \\
\text { (2012) [31] }\end{array}$ & $\begin{array}{l}\text { Filtered aqueous extract of } \\
\text { Terminalia chebula fruit } \\
\text { powder. }\end{array}$ & $\begin{array}{l}10 \mathrm{mM} \text {, room temp. } \\
1 \mathrm{ml} / 25 \mathrm{ml}, \mathrm{pH}: 4-9 \text {, } \\
\text { Static }\end{array}$ & $\begin{array}{l}\text { UV-Vis } \\
\text { FTIR } \\
\text { HR-TEM } \\
\text { XRD } \\
\text { EDS } \\
\text { DLS } \\
\text { ZP }\end{array}$ & $\begin{array}{l}\text { Size-25 nm } \\
\text { Structure-FCC } \\
\text { Nature-phyto } \\
\text { capped }\end{array}$ & $\begin{array}{l}\text { Stabile for } 10 \text { days, } \\
\text { AgNps showed } \\
\text { catalytic activity on the } \\
\text { reduction of } \\
\text { methylene blue. }\end{array}$ \\
\hline 49 & $\begin{array}{l}\text { Kaviya et al. (2012) } \\
\text { [68] }\end{array}$ & $\begin{array}{l}\text { Aqueous filtrate of } \\
\text { Crossandra } \\
\text { infundibuliformis leaf }\end{array}$ & $\begin{array}{l}1 \mathrm{mM}, 1 \mathrm{hr} \text {, } \\
\text { room temp, } \\
3 \mathrm{ml} / 40 \mathrm{ml}, \\
\text { Stirring, } \\
20 \text { min at } 4000 \mathrm{rpm}\end{array}$ & $\begin{array}{l}\text { UV-Vis. } \\
\text { FTIR } \\
\text { FESEM-EDAX } \\
\text { XRD }\end{array}$ & $\begin{array}{l}\text { Size- } \sim 38 \mathrm{~nm} \\
\text { Shape-flake } \\
\text { Structure-FCC }\end{array}$ & \\
\hline 50 & $\begin{array}{l}\text { Gopinath et al. } \\
\text { (2012) [111] }\end{array}$ & $\begin{array}{l}\text { Filtered aqueous extract of } \\
\text { Tribulus terrestris } L \text { dried } \\
\text { fruit }\end{array}$ & $\begin{array}{l}1 \mathrm{mM} \text {, room temp, dark, } \\
100 \mathrm{ml} / 150 \mathrm{ml}, \\
\text { Static }\end{array}$ & $\begin{array}{l}\text { UV-Vis } \\
\text { FTIR } \\
\text { TEM } \\
\text { XRD } \\
\text { AFM }\end{array}$ & $\begin{array}{l}\text { Size-16-28 nm } \\
\text { Shape-sph. } \\
\text { Structure-FCC. }\end{array}$ & $\begin{array}{l}\text { Stability- } 6 \text { months. } \\
\text { Antibacterial to S. pyogens, } P \text {. } \\
\text { aeruginosa, E. coli, S. aureus } \\
\text { and B. subtilis }\end{array}$ \\
\hline 51 & $\begin{array}{l}\text { Vijayaraghavan et al. } \\
\text { (2012) [65] }\end{array}$ & $\begin{array}{l}\text { Filtered aqueous extract of } \\
\text { Trachyspermum ammi and } \\
\text { Papavera } \\
\text { somniferum plant } \\
\text { powders }\end{array}$ & $\begin{array}{l}1 \mathrm{mM} \text {, } \\
\text { Trachyspermum ammi: } \\
15 \text { min, } \\
\text { Papavera } \\
\text { somniferum: } 35 \mathrm{~min}, 28^{\circ} \mathrm{C} \text {, } \\
1 \mathrm{ml} / 50 \mathrm{ml} \text {, } \\
\text { Shaking }\end{array}$ & $\begin{array}{l}\text { UV-Vis } \\
\text { SEM-EDAX }\end{array}$ & $\begin{array}{l}\text { Trachyspermum } \\
\text { ammi: } \\
\text { Size-87-998 } \mathrm{nm} \\
\text { Shape-tri } \\
\text { Papavera } \\
\text { somniferum: } \\
\text { Size-3.2 - } 7.6 \mu \mathrm{m} \\
\text { Shape-sph. }\end{array}$ & $\begin{array}{l}\text { Essential oil in } T \text {. ammi was } \\
\text { found to be good reducing } \\
\text { agent when compared to } \\
\text { alkaloids in } \\
P \text {. somniferum. }\end{array}$ \\
\hline
\end{tabular}




\section{Continued}

\begin{tabular}{|c|c|c|c|c|c|c|}
\hline 52 & $\begin{array}{l}\text { Sreekanth et al. } \\
\text { (2012) [69] }\end{array}$ & $\begin{array}{l}\text { Dioscorea batatas } \\
\text { rhizome powder }\end{array}$ & $\begin{array}{l}1 \mathrm{mM}, 25 \text { and } 80^{\circ} \mathrm{C} \\
\text { Static, } \\
20 \mathrm{~min} \text { at } 5000 \mathrm{rpm}\end{array}$ & $\begin{array}{l}\text { UV-Vis } \\
\text { FTIR } \\
\text { SEM } \\
\text { XRD }\end{array}$ & $\begin{array}{l}\text { Shape-circular and } \\
\text { flower } \\
\text { Structure-FCC } \\
\text { Nature-MD }\end{array}$ & \\
\hline 53 & $\begin{array}{l}\text { Chaudhary et al. } \\
\text { (2012) [112] }\end{array}$ & $\begin{array}{l}\text { Aqueous filtrate of Vitis } \\
\text { viniera fruit }\end{array}$ & $\begin{array}{l}1 \mathrm{mM}, 10 \mathrm{hr} \text {, room temp. } \\
10 \mathrm{ml} / 90 \mathrm{ml} \text {, } \\
\text { Static. } 15 \mathrm{~min} \text { at } 2000 \mathrm{rpm}\end{array}$ & $\begin{array}{l}\text { UV-Vis } \\
\text { SEM } \\
\text { XRD }\end{array}$ & $\begin{array}{l}\text { Size-10 - } 880 \mathrm{~nm} \\
\text { Shape-sph } \\
\text { Structure-FCC, } \\
\text { cubic and hexl }\end{array}$ & $\begin{array}{l}\text { Antibacterial to B. subtilis, E. } \\
\text { coli, P. aeruginosa and } S \text {. } \\
\text { pnemoniae }\end{array}$ \\
\hline 54 & $\begin{array}{l}\text { Ashok kumar (2012) } \\
\text { [113] }\end{array}$ & $\begin{array}{l}\text { Aqueous filtrate of } \\
\text { Prathemium } \\
\text { hysterophorus plant }\end{array}$ & $\begin{array}{l}1 \mathrm{mM}, 24 \mathrm{hr} \text {, room temp. } \\
1 \mathrm{ml} / 9 \mathrm{ml} \text {, } \\
\text { Static, } \\
20 \mathrm{~min} \text { at } 5000 \mathrm{rpm}\end{array}$ & $\begin{array}{l}\text { UV-Vis } \\
\text { FTIR } \\
\text { SEM } \\
\text { XRD }\end{array}$ & $\begin{array}{l}\text { Size—avg } 10 \mathrm{~nm} \\
\text { Shape-nearly sph } \\
\text { Structure-FCC }\end{array}$ & \\
\hline \multirow[t]{2}{*}{55} & $\begin{array}{l}\text { Patil et al. (2012) } \\
\text { [33] }\end{array}$ & $\begin{array}{l}\text { Filtered aqueous extract of } \\
\text { Ocimum tenuiflorum leaf }\end{array}$ & $\begin{array}{l}1 \mathrm{mM}, 10 \mathrm{~min} \text {, room temp. } \\
2 \mathrm{ml} / 20 \mathrm{ml} \text {, } \\
\text { Static }\end{array}$ & $\begin{array}{l}\text { UV-Vis } \\
\text { TEM } \\
\text { PS } \\
\text { ZP }\end{array}$ & $\begin{array}{l}\text { Size-15-25 nm } \\
\text { Shape-sph } \\
\text { Structure-FCC }\end{array}$ & $\begin{array}{l}\text { Antibacterial against } E \text {. coli, } \\
\text { C. bacterium, B. subtilis }\end{array}$ \\
\hline & $\begin{array}{l}\text { Arunachalam et al. } \\
\text { (2013) [114] }\end{array}$ & $\begin{array}{l}\text { Indigofera } \\
\text { aspalathoides, } \\
\text { aqueos leaf t } \\
\text { extracts }\end{array}$ & & $\begin{array}{l}\text { UV Vis } \\
\text { SEM } \\
\text { EDAX } \\
\text { FTIR }\end{array}$ & Size $-20-50 \mathrm{~nm}$ & $\begin{array}{l}\text { Water-soluble } \\
\text { organics leaf extract } \\
\text { responsible to } \\
\text { reduction. Wound healing } \\
\text { applications }\end{array}$ \\
\hline 56 & $\begin{array}{l}\text { Mubarakali et al. } \\
\text { (2011) [115] }\end{array}$ & $\begin{array}{l}\text { Filtered aqueous extract of } \\
\text { Mentha piperita plant } \\
\text { powder }\end{array}$ & $\begin{array}{l}1 \mathrm{mM}, 24 \mathrm{hr}, 28^{\circ} \mathrm{C}, \\
1.5 \mathrm{ml} / 30 \mathrm{ml} \text {, } \\
\text { Static, } 10 \mathrm{~min} \text { at } 6000 \mathrm{rpm}\end{array}$ & $\begin{array}{l}\text { UV-Vis } \\
\text { FTIR } \\
\text { SEM } \\
\text { EDS }\end{array}$ & $\begin{array}{l}\text { Size-90 } \mathrm{nm} \\
\text { Shape-sph. }\end{array}$ & $\begin{array}{l}\text { Active against } \\
\text { clinically isolated human } \\
\text { pathogens like } E \text {. coli and } S . \\
\text { aureus. }\end{array}$ \\
\hline 57 & $\begin{array}{l}\text { Mukunthan et al. } \\
\text { (2011) [32] }\end{array}$ & $\begin{array}{l}\text { Aqueous extract of } \\
\text { Catharanthus } \\
\text { roseus leaf }\end{array}$ & $\begin{array}{l}1 \mathrm{mM}, 15 \mathrm{~min}, 80^{\circ} \mathrm{C} \text {, } \\
10 \mathrm{ml} / 90 \mathrm{ml}, \\
\text { Static }\end{array}$ & $\begin{array}{l}\text { UV-Vis } \\
\text { SEM } \\
\text { XRD } \\
\text { EDAX }\end{array}$ & $\begin{array}{l}\text { Size-48 - } 67 \mathrm{~nm} \\
\text { Structure-FCC } \\
\text { Nature-uniform }\end{array}$ & $\begin{array}{l}\text { Antibacterial activity against } \\
\text { S. aureus, E. coli, K. } \\
\text { pneumoniae, B. aureus and } P . \\
\text { aeruginosa }\end{array}$ \\
\hline 58 & $\begin{array}{l}\text { Rajakumar and } \\
\text { Abdul Rahuman } \\
\text { (2011) [70] }\end{array}$ & $\begin{array}{l}\text { Filtered aqueous extract of } \\
\text { Eclipta prostrate leaf }\end{array}$ & $\begin{array}{l}1 \mathrm{mM}, 1 \mathrm{hr} \text {, room temp. } \\
12 \mathrm{ml} / 88 \mathrm{ml}, \\
45 \mathrm{~min} \text { at } 10000 \mathrm{rpm} \text {, } \\
\text { Static }\end{array}$ & $\begin{array}{l}\text { UV-Vis } \\
\text { FTIR } \\
\text { SEM } \\
\text { TEM } \\
\text { XRD }\end{array}$ & $\begin{array}{l}\text { Size-35 - } 60 \mathrm{~nm} \\
\text { Shape-TEM: sph. } \\
\text { SEM: triang, hex } \\
\text { and pentagon } \\
\text { Structure- } \\
\text { crystalline } \\
\text { Nature-biphasic }\end{array}$ & $\begin{array}{l}\text { Stabile for } 6 \mathrm{hr} \\
\text { Larvicidal to filariasis vector } \\
\text { C. quinquefasciatus and } \\
\text { malarial vector A. subpictus }\end{array}$ \\
\hline 59 & $\begin{array}{l}\text { Kumar and Yadav. } \\
\text { (2011) [116] }\end{array}$ & $\begin{array}{l}\text { Filtered aqueous extract of } \\
\text { Lonicera japonica } L \text { leaf. }\end{array}$ & $\begin{array}{l}1 \text { to } 9 \mathrm{mM}, 24 \mathrm{hr} \text {, } \\
40^{\circ} \mathrm{C}-80^{\circ} \mathrm{C} \text {, } \\
5 \% \text { to } 40 \%(\mathrm{v} / \mathrm{v}) \\
\text { Static, } 5 \mathrm{~min} \text { at } 10000 \mathrm{rpm}\end{array}$ & $\begin{array}{l}\text { UV-Vis } \\
\text { FTIR } \\
\text { SEM } \\
\text { TEM } \\
\text { AFM } \\
\text { ZP }\end{array}$ & $\begin{array}{l}\text { Size-36 - } 72 \mathrm{~nm} \\
\text { Shape-sph, plate, } \\
\text { and other shaped }\end{array}$ & $\begin{array}{l}\text { Stability: zeta } \\
\text { potential— } 41 \mathrm{mV}\end{array}$ \\
\hline 60 & $\begin{array}{l}\text { Gnanadesigan et al. } \\
\text { (2011) [117] }\end{array}$ & $\begin{array}{l}\text { Filtered aqueous extract of } \\
\text { Rizophora } \\
\text { mucronata leaf }\end{array}$ & $\begin{array}{l}1 \mathrm{M}, 10 \mathrm{~min} \text {, room temp. } \\
10 \mathrm{ml} / 90 \mathrm{ml} \text {, } \\
20 \mathrm{~min} \text { at } 12000 \mathrm{rpm} \text {, } \\
\text { Static }\end{array}$ & $\begin{array}{l}\text { UV-Vis } \\
\text { FTIR } \\
\text { XRD } \\
\text { AFM }\end{array}$ & $\begin{array}{l}\text { Size-60-95 nm } \\
\text { Shape-sph. } \\
\text { Structure-cryst }\end{array}$ & $\begin{array}{l}\text { Larvicidal to Ae. aegypti and } \\
\text { Cx. quinquefasciatus }\end{array}$ \\
\hline 61 & $\begin{array}{l}\text { Rani and Reddy } \\
\text { (2011) [118] }\end{array}$ & $\begin{array}{l}\text { Decanted aqueous extract } \\
\text { of Piper betel } L \text {. leaf }\end{array}$ & $\begin{array}{l}1 \mathrm{mM}, 1 \mathrm{~min} \text { to } 2 \mathrm{hr} \text {, room } \\
\text { temp, sunlight, } \\
10 \mathrm{ml} / 190 \mathrm{ml} \text {, } \\
\text { Static, } \\
15 \mathrm{~min} \text { at } 6000 \mathrm{rpm} \text {. }\end{array}$ & $\begin{array}{l}\text { UV-Vis } \\
\text { FTIR } \\
\text { TEM } \\
\text { XRD }\end{array}$ & $\begin{array}{l}\text { Sunlight: } 5 \mathrm{~min} . \\
\text { Size- 120 nm } \\
\text { Shape-irregular } \\
\text { Structure-FCC } \\
\text { Nature- } \\
\text { agglomerated } \\
\text { Sunlight: } 10-80 \mathrm{~min} \\
\text { Size-28 - } 17 \mathrm{~nm} \\
\text { Shape-sph. } \\
\text { Structure-FCC } \\
\text { Nature-shelled } \\
\text { AgNP }\end{array}$ & $\begin{array}{l}\text { AgNP toxic to aquatic plant } \\
D \text {. magna. } \\
\text { Biosynthesized AgNP less } \\
\text { toxic compared to chemically } \\
\text { synthesized ones }\end{array}$ \\
\hline 62 & $\begin{array}{l}\text { Veerasamy et al. } \\
\text { (2011) [119] }\end{array}$ & $\begin{array}{l}\text { Aqueous filtrate of } \\
\text { Garcinia mangostana leaf }\end{array}$ & $\begin{array}{l}0.25-5 \mathrm{mM}, 0-70 \mathrm{~min} \text {, } \\
37^{\circ} \mathrm{C}-90^{\circ} \mathrm{C} \text {, } \\
5 \mathrm{ml} / 95 \mathrm{ml} \text {, } \\
\text { Static, } \mathrm{pH}-4,7,8 \\
30 \mathrm{~min}(5 \mathrm{k} \mathrm{rpm})\end{array}$ & $\begin{array}{l}\text { UV-Vis } \\
\text { FTIR } \\
\text { TEM }\end{array}$ & $\begin{array}{l}\text { Size—avg } 35 \mathrm{~nm} \\
\text { Shape—sph }\end{array}$ & $\begin{array}{l}\text { Stable for } 30 \text { days, } \\
\text { Antibacterial against E. coli } \\
\text { and S. aureus }\end{array}$ \\
\hline 63 & $\begin{array}{l}\text { Santoshkumar et al. } \\
\text { (2011) [120] }\end{array}$ & $\begin{array}{l}\text { Decanted aqueous filtrate } \\
\text { of Nelumbo nucifera leaf }\end{array}$ & $\begin{array}{l}1 \mathrm{mM}, 10 \mathrm{~min} \text {, room temp. } \\
12 \mathrm{~m} / 8 \mathrm{ml} \text {, } \\
\text { Static }\end{array}$ & $\begin{array}{l}\text { UV-Vis } \\
\text { FTIR } \\
\text { TEM } \\
\text { XRD }\end{array}$ & $\begin{array}{l}\text { Size-25 - } 80 \mathrm{~nm} \\
\text { Shape-sph, tri and } \\
\text { dec } \\
\text { Structure-FCC }\end{array}$ & $\begin{array}{l}\text { Larvicidal against } A \text {. } \\
\text { subpictus and } C . \\
\text { quinquefasciatus }\end{array}$ \\
\hline 64 & $\begin{array}{l}\text { Ahmad et al. (2011) } \\
\text { [121] }\end{array}$ & $\begin{array}{l}\text { Aqueous extract of } \\
\text { Desmodium } \\
\text { triflorum }\end{array}$ & $0.025 \mathrm{M}, 1 \mathrm{hr}$ & $\begin{array}{l}\text { UV-Vis } \\
\text { TEM } \\
\text { XRD } \\
\text { UV-Vis }\end{array}$ & $\begin{array}{l}\text { Size-5 - } 20 \mathrm{~nm} \\
\text { Structure-cryst }\end{array}$ & $\begin{array}{l}\text { Antibacterial against } S . s p p \text {, } \\
\text { E. coli, B. subtilis }\end{array}$ \\
\hline 65 & $\begin{array}{l}\text { Prathna et al. (2011) } \\
\text { [122] }\end{array}$ & $\begin{array}{l}\text { Filtered and centrifuged } \\
\text { juice of } \\
\text { Citruslimon fruit }\end{array}$ & $\begin{array}{l}0.1-10 \mathrm{mM}, 4 \mathrm{hr}, 30^{\circ} \mathrm{C} \text {, } \\
1: 4 \text { to } 4: 1, \\
\text { Shaken, } \\
10 \text { min at } 10000 \mathrm{rpm}\end{array}$ & $\begin{array}{l}\text { XRD } \\
\text { TEM } \\
\text { FTIR } \\
\text { AFM } \\
\text { DLS } \\
\text { ZP }\end{array}$ & $\begin{array}{l}\text { Size— } 50 \mathrm{~nm} \\
\text { Shape—nearly sph. } \\
\text { Structure—cryst } \\
\text { Nature-PD }\end{array}$ & $\begin{array}{l}\text { AgNPs were stable for } 14 \\
\text { days. Size-XRD-18.306 nm } \\
\text { AFM-<100 nm } \\
\text { TEM-25-50 nm } \\
\text { DLS-153.68 nm }\end{array}$ \\
\hline 66 & $\begin{array}{l}\text { Bankar et al } \\
\text { (2010) [50] }\end{array}$ & $\begin{array}{l}\text { Acetone treated, aqueous } \\
\text { extracted, filtered and } \\
\text { precipitated powder of } \\
\text { Banana peel }\end{array}$ & $\begin{array}{l}0.125 \text { to } 1 \mathrm{mM}, 3 \mathrm{~min} \text {, } \\
40^{\circ} \mathrm{C} \text { to } 100^{\circ} \mathrm{C}, \\
0.5 \text { to } 10 \mathrm{mg} / 2 \mathrm{ml} \text {, } \\
\text { pH: } 2-5, \\
\text { Static }\end{array}$ & $\begin{array}{l}\text { UV-Vis } \\
\text { FTIR. } \\
\text { SEM-EDS } \\
\text { XRD }\end{array}$ & $\begin{array}{l}\text { Size- }<100 \mathrm{~nm} \\
\text { Structure-FCC }\end{array}$ & $\begin{array}{l}\text { Antifungal and } \\
\text { antibacterial action }\end{array}$ \\
\hline 67 & $\begin{array}{l}\text { Njagi et al. } \\
\text { (2010) [123] }\end{array}$ & $\begin{array}{l}\text { Filtered aqueous extract of } \\
\text { Sorghum bran }\end{array}$ & $\begin{array}{l}0.1 \mathrm{M}, 1 \mathrm{~min} \text {, room temp. } \\
2: 1 \text { volume ratio, } \\
\text { Shaken }\end{array}$ & $\begin{array}{l}\text { UV-Vis } \\
\text { FE-SEM } \\
\text { HR-TEM-EDS } \\
\text { XRD }\end{array}$ & $\begin{array}{l}\text { Size-10 nm } \\
\text { Shape-sph. } \\
\text { Structure-FCC } \\
\text { Nature-uniform } \\
\text { nano clusters }\end{array}$ & $\begin{array}{l}\text { AgNP of smaller size at } 50^{\circ} \mathrm{C} \\
\text { of extraction } \\
\text { temperature compared to } 25^{\circ} \mathrm{C} \\
\text { and } 80^{\circ} \mathrm{C}\end{array}$ \\
\hline
\end{tabular}




\section{Continued}

\begin{tabular}{|c|c|c|c|c|c|c|}
\hline 68 & $\begin{array}{l}\text { Kumar et al. } \\
\text { (2010) [124] }\end{array}$ & $\begin{array}{l}\text { Filtered aqueous extract of } \\
\text { Syzygium cumini leaf (LE) } \\
\text { and seed (SE) powder }\end{array}$ & $\begin{array}{l}1 \mathrm{mM}, 24 \mathrm{hr} \text {, room temp. } \\
10 \%(\mathrm{v} / \mathrm{v}) \\
\text { Static, } \\
20 \mathrm{~min}, 12 \mathrm{k} \mathrm{rpm}\end{array}$ & $\begin{array}{l}\text { UV-Vis } \\
\text { FTIR } \\
\text { SEM } \\
\text { AFM }\end{array}$ & $\begin{array}{l}\text { Size-LE: } 30 \mathrm{~nm} \text {, } \\
\text { Water content of } \\
\text { LE: } 29 \mathrm{~nm}, \mathrm{SE}: 92 \\
\text { nm, Water content } \\
\text { of LE: } 73 \mathrm{~nm} \text {. }\end{array}$ & $\begin{array}{l}\text { SE have higher synthesis rates } \\
\text { and larger size AgNP } \\
\text { compared to LE. }\end{array}$ \\
\hline 69 & $\begin{array}{l}\text { Dubey et al. } \\
\text { (2010) [79] }\end{array}$ & $\begin{array}{l}\text { Filtered aqueous extract of } \\
\text { Tanaetum vulgare fruit. }\end{array}$ & $\begin{array}{l}1-3 \mathrm{mM}, 10 \mathrm{~min}-5 \mathrm{hr}, \\
25^{\circ} \mathrm{C}-150^{\circ} \mathrm{C}, \\
0.5-4.8 \mathrm{ml} / 50 \mathrm{ml}, \\
\text { pH: } 2-10 \text {, } \\
\text { Static }\end{array}$ & $\begin{array}{l}\text { UV-Vis } \\
\text { FTIR } \\
\text { TEM } \\
\text { XRD } \\
\text { EDAX }\end{array}$ & $\begin{array}{l}\text { Size-10 - } 40 \mathrm{~nm} \\
\text { Shape-sph. } \\
\text { Structure-FCC }\end{array}$ & $\begin{array}{l}\text { AgNP more stable in basic } \\
\text { compared to acidic medium }\end{array}$ \\
\hline 70 & $\begin{array}{l}\text { Shukla et al. } \\
\text { (2010) [37] }\end{array}$ & $\begin{array}{l}\text { Filtered aqueous extract of } \\
\text { Piper nigrum (black } \\
\text { pepper) }\end{array}$ & $\begin{array}{l}10 \mathrm{mM} \text {, room temp. } \\
1 \mathrm{ml} / 100 \mathrm{ml} \text {, } \\
\text { Stirred, } \\
10 \mathrm{~min} \text { at } 3000 \mathrm{rpm}\end{array}$ & $\begin{array}{l}\text { UV-Vis } \\
\text { TEM } \\
\text { XRD }\end{array}$ & $\begin{array}{l}\text { Size-20 - } 50 \mathrm{~nm} \\
\text { Shape-sph. } \\
\text { Structure-FCC } \\
\text { Nature-large grain, } \\
\text { WD, uniform and } \\
\text { polycrystalline }\end{array}$ & \\
\hline 71 & $\begin{array}{l}\text { Krishnaraj et al. } \\
\text { (2010) [125] }\end{array}$ & $\begin{array}{l}\text { Aqueous filtrate of } \\
\text { Acalypha indica leaf }\end{array}$ & $\begin{array}{l}1 \mathrm{mM}, 30 \mathrm{~min}, 37^{\circ} \mathrm{C} \text {, } \\
\text { dark } 12 \mathrm{ml} / 100 \mathrm{ml} \text {, } \\
\text { Static, } \\
30 \mathrm{~min} \text { at } 75000 \mathrm{~g}\end{array}$ & $\begin{array}{l}\text { UV-Vis } \\
\text { SEM } \\
\text { TEM } \\
\text { EDS } \\
\text { XRD }\end{array}$ & $\begin{array}{l}\text { Size-20 - } 30 \mathrm{~nm} \\
\text { Structure-cub }\end{array}$ & $\begin{array}{l}\text { Antimicrobial against water } \\
\text { borne pathogens E. coli and } \\
\text { Vibrio cholera }\end{array}$ \\
\hline 72 & $\begin{array}{l}\text { Satish kumar et al. } \\
\text { (2009) [38] }\end{array}$ & $\begin{array}{l}\text { Aqueous bark and powder } \\
\text { extracts of Cinnamon } \\
\text { zeylanicum plant }\end{array}$ & $\begin{array}{l}1 \mathrm{mM}, 25^{\circ} \mathrm{C} \text {, } \\
1 \text { to } 5 \mathrm{ml} / 50 \mathrm{ml} \text {, } \\
\text { Powder content: } \\
0.1 \text { to } 1 \mathrm{~g} / 50 \mathrm{ml} \text {, } \\
\text { pH: } 11 \text {, } 11 \text {, } \\
\text { Shaken }\end{array}$ & $\begin{array}{l}\text { UV-Vis } \\
\text { TEM } \\
\text { XRD } \\
\text { EDX }\end{array}$ & $\begin{array}{l}\text { Size-powder: } 31 \\
\text { nm, Extract: } 40 \mathrm{~nm} \\
\text { Shape-quasi sph } \\
\text { and R, Structure- } \\
\text { cub and hex } \\
\text { Nature-bi-phasic }\end{array}$ & $\begin{array}{l}\text { Stable for } 3 \text { months, } \\
\text { Served as antimicrobial agents }\end{array}$ \\
\hline 73 & $\begin{array}{l}\text { Tripathi et al. (2009) } \\
\text { [34] }\end{array}$ & $\begin{array}{l}\text { Aqueous filtrate of } \\
\text { Azadirachta indica leaves }\end{array}$ & $\begin{array}{l}10 \mathrm{mM}, 24 \mathrm{hr}, 28^{\circ} \mathrm{C} \text {, } \\
1: 4.15 \mathrm{~min} \text { at } 10,000 \mathrm{rpm} \\
\text { Shaken }\end{array}$ & $\begin{array}{l}\text { UV-Vis } \\
\text { TEM } \\
\text { SEM } \\
\text { FTIR }\end{array}$ & $\begin{array}{l}\text { Size-50-100 nm } \\
\text { Shape-irregular } \\
\text { Nature-PD }\end{array}$ & $\begin{array}{l}\text { AgNPs loaded on cotton disks } \\
\text { shown antibacterial activity. }\end{array}$ \\
\hline 74 & $\begin{array}{l}\text { Leela and } \\
\text { Vivekanandan. } \\
\text { (2008) [126] }\end{array}$ & $\begin{array}{l}\text { Aqueous extract of } \\
\text { Helianthus annus plant }\end{array}$ & & $\begin{array}{l}\text { UV-Vis } \\
\text { XRD } \\
\text { SEM }\end{array}$ & Structure-cryst & \\
\hline 75 & $\begin{array}{l}\text { Chandran et al. } \\
\text { (2006) [30] }\end{array}$ & $\begin{array}{l}\text { Aqueous extract of Aloe } \\
\text { vera leaf }\end{array}$ & $\begin{array}{l}1 \mathrm{mM}, 24 \mathrm{hr} \text {, room temp. } \\
5 \mathrm{ml} / 5 \mathrm{ml} \text {, } \\
\text { Static }\end{array}$ & $\begin{array}{l}\text { UV-Vis } \\
\text { XRD } \\
\text { TEM }\end{array}$ & $\begin{array}{l}\text { Size- } 15.2 \pm 4.2 \mathrm{~nm} \\
\text { Shape-sph. } \\
\text { Structure-FCC }\end{array}$ & \\
\hline 76 & $\begin{array}{l}\text { Ankamwar et al. } \\
\text { (2005) [35] }\end{array}$ & $\begin{array}{l}\text { Emblica Officinalis fruit } \\
\text { extract }\end{array}$ & & $\begin{array}{l}\text { UV-Vis } \\
\text { TEM }\end{array}$ & Size $-10-20 \mathrm{~nm}$ & $\begin{array}{l}\text { Transmetallation reaction } \\
\text { promoted the AgNPs } \\
\text { synthesis }\end{array}$ \\
\hline 77 & $\begin{array}{l}\text { Shankar et al. (2004) } \\
\text { [127] }\end{array}$ & $\begin{array}{l}\text { Decanted aqueous extract } \\
\text { of Azadirachta } \\
\text { indica leaf }\end{array}$ & $\begin{array}{l}1 \mathrm{mM}, 24 \mathrm{hr} \\
5 \mathrm{ml} / 45 \mathrm{ml} \text {, } \\
15 \mathrm{~min} \text { at } 10000 \mathrm{rpm} . \\
\text { Static }\end{array}$ & $\begin{array}{l}\text { UV-Vis } \\
\text { XRD } \\
\text { TEM } \\
\text { FTIR }\end{array}$ & $\begin{array}{l}\text { Size-5 - } 35 \mathrm{~nm} \\
\text { Shape-Sph } \\
\text { Structure-cryst } \\
\text { Nature-PD }\end{array}$ & AgNPs stable for 4 weeks \\
\hline 78 & $\begin{array}{l}\text { Shankar et al. (2003) } \\
\text { [42] }\end{array}$ & $\begin{array}{l}\text { Decanted aqueous broth } \\
\text { of Pelargonium } \\
\text { graveolens leaf }\end{array}$ & $\begin{array}{l}1 \mathrm{mM}, 24 \mathrm{hr} \\
5 \mathrm{ml} / 100 \mathrm{ml} \text {, } \\
15 \mathrm{~min} \text { at } 10000 \mathrm{rpm} . \\
\text { Static }\end{array}$ & $\begin{array}{l}\text { UV-Vis } \\
\text { XRD } \\
\text { FTIR } \\
\text { TEM } \\
\text { EDAX }\end{array}$ & $\begin{array}{l}\text { Size-16 - } 20 \mathrm{~nm} \text {. } \\
\text { Shape-nearly sph } \\
\text { Structure-FCC } \\
\text { Nature-PD }\end{array}$ & $\begin{array}{l}\text { Chlorophyll of leaf extract } \\
\text { formed } 5 \mathrm{~nm} \text { capping around } \\
\text { the AgNP. }\end{array}$ \\
\hline \multicolumn{7}{|c|}{ Fungi } \\
\hline 79 & $\begin{array}{l}\text { Das et al. } \\
\text { (2012) [76] }\end{array}$ & $\begin{array}{l}\text { Mycelia of Rhizopus } \\
\text { oryzae }\end{array}$ & $\begin{array}{l}1 \text { to } 5 \mathrm{mM}, 72 \mathrm{hr}, 30^{\circ} \mathrm{C} \text {, } \\
0.2 \mathrm{~g} / 25 \mathrm{ml} \text {. } \\
\text { pH }-2 \text { to } 8 \text {, } \\
\text { Shaken }\end{array}$ & $\begin{array}{l}\text { UV-Vis } \\
\text { FTIR } \\
\text { HRTEM } \\
\text { EDAX }\end{array}$ & $\begin{array}{l}\text { Size— } 15 \mathrm{~nm} \\
\text { Shape-sph. } \\
\text { Structure-FCC }\end{array}$ & $\begin{array}{l}\text { Stable for } 3 \text { months, } \\
\text { Antimicrobial to } E \text {. coli and } \\
\text { B. subtilis, Used for treating } \\
\text { contaminated water } \\
\text { and adsorption of pesticides }\end{array}$ \\
\hline 80 & $\begin{array}{l}\text { Naveen et al (2010) } \\
\text { [128] }\end{array}$ & $\begin{array}{l}\text { Aqueous cell filtrate of } \\
\text { Penicillium Sp. fungi }\end{array}$ & $\begin{array}{l}1 \mathrm{mM}, 24 \mathrm{hr} \text {, room temp, } \\
\text { dark } 50 \mathrm{ml} / 50 \mathrm{ml} \text {, Agitated, } \\
\text { Lyophilized }\end{array}$ & $\begin{array}{l}\text { UV-Vis } \\
\text { FTIR } \\
\text { AFM }\end{array}$ & Size-52- $104 \mathrm{~nm}$ & \\
\hline 81 & $\begin{array}{l}\text { Balaji et al (2009) } \\
\text { [129] }\end{array}$ & $\begin{array}{l}\text { Cladosporium clado } \\
\text { sporioides fungal } \\
\text { aqueous filtrate }\end{array}$ & $\begin{array}{l}78 \mathrm{~h}, 27^{\circ} \mathrm{C} .10 \mathrm{ml} \text {, } \\
\text { Shaken }\end{array}$ & $\begin{array}{l}\text { UV-Vis } \\
\text { TEM } \\
\text { XRD } \\
\text { FTIR }\end{array}$ & $\begin{array}{l}\text { Size—Avg: } 35 \mathrm{~nm} \\
\text { Shape-Sph. } \\
\text { Structure-FCC } \\
\text { Nature-PD }\end{array}$ & \\
\hline 82 & $\begin{array}{l}\text { Shaligram et al } \\
\text { (2009) [130] }\end{array}$ & $\begin{array}{l}\text { Penicillium } \\
\text { brevicompatum WA } 2315 \\
\text { fungal aqueous filtrate }\end{array}$ & $\begin{array}{l}1 \mathrm{mM}, 72 \mathrm{hr}, 25^{\circ} \mathrm{C} \text {, } \\
\text { Shaken }\end{array}$ & $\begin{array}{l}\text { UV-Vis } \\
\text { FTIR } \\
\text { TEM } \\
\text { XRD }\end{array}$ & $\begin{array}{l}\text { Size}-58.35 \pm 17.8 \\
\mathrm{~nm} \\
\text { Structure-FCC }\end{array}$ & \\
\hline 83 & $\begin{array}{l}\text { Fayaz et al. (2009) } \\
\text { [82] }\end{array}$ & $\begin{array}{l}\text { Harvested cell aqueous } \\
\text { filtrate of Trichoderma } \\
\text { viride fungus }\end{array}$ & $\begin{array}{l}1 \mathrm{mM} \text {, dark, } 10^{\circ} \mathrm{C}-40^{\circ} \mathrm{C} . \\
\text { Shaken. }\end{array}$ & $\begin{array}{l}\text { UV-Vis } \\
\text { XRD } \\
\text { TEM } \\
\text { FTIR }\end{array}$ & $\begin{array}{l}10^{\circ} \mathrm{C}: 2-4 \mathrm{~nm}, \mathrm{sph} . \\
27^{\circ} \mathrm{C}: \\
10-40 \mathrm{~nm} \text {, sph. } \\
40^{\circ} \mathrm{C}: \\
80-100 \mathrm{~nm} \text {, Plate } \\
\text { like, Structure: } \\
\text { Cryst, Nature: } \mathrm{MD}\end{array}$ & $\begin{array}{l}\text { Increase in } \\
\text { temperature led to blue shift } \\
\text { in UV-Vis peak, decreased } \\
\text { size and increased } \\
\text { dispersity }\end{array}$ \\
\hline 84 & $\begin{array}{l}\text { Kathiresan et al. } \\
\text { (2009) [131] }\end{array}$ & $\begin{array}{l}\text { Aqueous Cell } \\
\text { filtrate of } \\
\text { Penicillum } \\
\text { fellutanum fungus }\end{array}$ & $\begin{array}{l}0.5-2.5 \mathrm{mM}, 0-48 \mathrm{hr} \text {, } \\
0^{\circ} \mathrm{C}-40^{\circ} \mathrm{C} \text {, dark, } \\
\text { pH: } 5-7.5 . \\
\text { Salinity- } 1 \%-5 \% \mathrm{NaCl} \text {, } \\
\text { Shaken }\end{array}$ & $\begin{array}{l}\text { UV-Vis } \\
\text { TEM }\end{array}$ & $\begin{array}{l}\text { Size }-5-25 \mathrm{~nm} \\
\text { Shape-Sph. }\end{array}$ & $\begin{array}{l}\left(\mathrm{NH}_{4}\right)_{2} \mathrm{SO}_{4} \text { solid used for } \\
\text { precipitation and phosphate } \\
\text { buffer }(\mathrm{pH}-8) \text { for dissolution } \\
\text { of nanoparticles }\end{array}$ \\
\hline 85 & $\begin{array}{l}\text { Ingle et al (2009) } \\
\text { [57] }\end{array}$ & $\begin{array}{l}\text { Aqueous cell } \\
\text { filtrate of Fusarium solani } \\
\text { fungus }\end{array}$ & $\begin{array}{l}1 \mathrm{mM} \text {, room temp. } \\
\text { Static, } \\
10 \mathrm{~min}, 10000 \mathrm{~g}\end{array}$ & $\begin{array}{l}\text { UV-Vis } \\
\text { FTIR } \\
\text { TEM }\end{array}$ & $\begin{array}{l}\text { Size-5 - } 35 \mathrm{~nm} \\
\text { Shape-Sph. }\end{array}$ & \\
\hline 86 & $\begin{array}{l}\text { Basavaraja et al } \\
\text { (2008) [132] }\end{array}$ & $\begin{array}{l}\text { Aqueous filtrate of } \\
\text { Fusarium } \\
\text { semitetum fungus }\end{array}$ & $\begin{array}{l}1 \mathrm{mM}, 48 \mathrm{hr}, 27^{\circ} \mathrm{C} \text {, } \\
\text { Shaken }\end{array}$ & $\begin{array}{l}\text { UV-Vis } \\
\text { XRD } \\
\text { TEM } \\
\text { FTIR }\end{array}$ & $\begin{array}{l}\text { Size-10 - } 60 \mathrm{~nm} \\
\text { Shape-Sph. } \\
\text { Structure-cryst } \\
\text { Nature-PD }\end{array}$ & AgNP stable for 6 - 8 weeks \\
\hline
\end{tabular}




\section{Continued}

\begin{tabular}{|c|c|c|c|c|c|c|}
\hline 87 & $\begin{array}{l}\text { Vigneswaran et al. } \\
\text { [66] }\end{array}$ & $\begin{array}{l}\text { Asphergillus flavus fungal } \\
\text { cells }\end{array}$ & $\begin{array}{l}1 \mathrm{mM}, 24 \mathrm{hr}, 37^{\circ} \mathrm{C} \text {, } \\
\text { Dark. } 5 \mathrm{~g} / 100 \mathrm{ml} \text {, } \\
\text { Shaken }\end{array}$ & $\begin{array}{l}\text { UV-Vis } \\
\text { TEM } \\
\text { XRD } \\
\text { FTIR } \\
\text { FS }\end{array}$ & $\begin{array}{l}\text { Size-8.92 } \pm 1.61 \\
\text { nm } \\
\text { Shape-Isotropic } \\
\text { Structure-FCC } \\
\text { Nature-MD }\end{array}$ & AgNP stable for 3 months \\
\hline 88 & $\begin{array}{l}\text { Bhainsa and D'souza } \\
\text { (2006) [54] }\end{array}$ & $\begin{array}{l}\text { Aspherillus } \\
\text { fumigates aqueous cell } \\
\text { filtrate }\end{array}$ & $\begin{array}{l}1 \mathrm{mM}, 1 \mathrm{hr}, 25^{\circ} \mathrm{C} \text {, } \\
\text { Dark, } \\
\text { Shaken }\end{array}$ & $\begin{array}{l}\text { UV—Vis } \\
\text { TEM } \\
\text { XRD }\end{array}$ & $\begin{array}{l}\text { Size-5 - } 25 \mathrm{~nm} \\
\text { Shape-Sph and Tri. } \\
\text { Structure-Crystal } \\
\text { Nature-WD }\end{array}$ & $\begin{array}{l}\text { No precipitation of AgNP } \\
\text { observed upto } 72 \text { hrs }\end{array}$ \\
\hline 89 & $\begin{array}{l}\text { Vigneswaran et al. } \\
\text { [67] }\end{array}$ & $\begin{array}{l}\text { Phaenerochaete } \\
\text { chrysosporium mycelium }\end{array}$ & $\begin{array}{l}1 \mathrm{mM}, 24 \mathrm{hr}, 37^{\circ} \mathrm{C} \text {, } \\
\text { Dark, } \\
\text { Shaken }\end{array}$ & $\begin{array}{l}\text { UV-Vis } \\
\text { XRD } \\
\text { SEM } \\
\text { TEM } \\
\text { FS }\end{array}$ & $\begin{array}{l}\text { Size-50 - } 200 \mathrm{~nm} \\
\text { Shape—sph. and hex. } \\
\text { Structure-FCC } \\
\text { Nature-non } \\
\text { uniform }\end{array}$ & $\begin{array}{l}\text { AgNP formed on the surface } \\
\text { of mycelium }\end{array}$ \\
\hline 90 & $\begin{array}{l}\text { Duran et al (2005) } \\
\text { [56] }\end{array}$ & $\begin{array}{l}\text { Aqueous filtrate and } \\
\text { biomass of Fusarium } \\
\text { oxysporum species. }\end{array}$ & $\begin{array}{l}1 \mathrm{mM}, 28 \mathrm{hr}, 28^{\circ} \mathrm{C} . \\
10 \mathrm{~g} / 100 \mathrm{ml} \\
\text { Static. }\end{array}$ & $\begin{array}{l}\text { UV-Vis } \\
\text { SEM }\end{array}$ & $\begin{array}{l}\text { Size-20 - } 50 \mathrm{~nm} \\
\text { Shape—sph. }\end{array}$ & $\begin{array}{l}\text { Nitrate based } \\
\text { reductase promoted the AgNP } \\
\text { synthesis }\end{array}$ \\
\hline 91 & $\begin{array}{l}\text { Senapati et al. } \\
\text { (2004) [133] }\end{array}$ & $\begin{array}{l}\text { Verticillium and } F . \\
\text { oxysporum }\end{array}$ & & $\begin{array}{l}\text { UV-Vis } \\
\text { SEM/TEM }\end{array}$ & $\begin{array}{l}\text { Size-Verticillium } \\
25 \pm 8 \mathrm{~nm} \text {, } \\
\text { F. oxysporum-5 - } \\
50 \mathrm{~nm}\end{array}$ & $\begin{array}{l}\text { Verticillium (intracellular) and } \\
\text { F. oxysporum - extracellular } \\
\text { synthesis. }\end{array}$ \\
\hline 92 & $\begin{array}{l}\text { Ahmad et al. (2003) } \\
\text { [55] }\end{array}$ & $\begin{array}{l}\text { Fusarium } \\
\text { oxysporum biomass }\end{array}$ & $\begin{array}{l}1 \mathrm{mM}, 72 \mathrm{hr} \text {, room temp, } \\
\text { dark } 10 \mathrm{~g} / 100 \mathrm{ml} \text {, } \\
\text { Static }\end{array}$ & $\begin{array}{l}\text { UV-Vis } \\
\text { XRD } \\
\text { TEM } \\
\text { FTIR } \\
\text { FS }\end{array}$ & $\begin{array}{l}\text { Size-5 - } 50 \mathrm{~nm} \\
\text { Shape—sph/tri. } \\
\text { Structure-FCC }\end{array}$ & \\
\hline 93 & $\begin{array}{l}\text { Mukherjee et al. } \\
\text { (2001) [52] }\end{array}$ & $\begin{array}{l}\text { Harvested mycelia of } \\
\text { Verticillium sp. fungi }\end{array}$ & $\begin{array}{l}0.2 \mathrm{mM}, 72 \mathrm{hr}, 28^{\circ} \mathrm{C} \text {, } \\
10 \mathrm{~g} / 100 \mathrm{ml}, \\
\text { Shaken, } \\
\text { pH: } 5.5-6\end{array}$ & $\begin{array}{l}\text { UV-Vis } \\
\text { SEM } \\
\text { TEM } \\
\text { EDAX }\end{array}$ & $\begin{array}{l}\text { Size-25 } \pm 12 \mathrm{~nm} \\
\text { Shape-nearly } \\
\text { sph, } \\
\text { Nature- } \\
\text { monodispersed }\end{array}$ & $\begin{array}{l}\text { AgNPs were } \\
\text { synthesized on } \\
\text { intracellular bases. }\end{array}$ \\
\hline \multicolumn{7}{|c|}{ Gram positive Bacteria } \\
\hline 94 & $\begin{array}{l}\text { Zhang et al. } \\
\text { (2014) [134] }\end{array}$ & $\begin{array}{l}\text { Lactobacillus } \\
\text { fermentum.LMG } 8900 \\
\text { cells }\end{array}$ & $\begin{array}{l}10 \mathrm{~g} / \mathrm{L}, 24 \mathrm{hr}, 30^{\circ} \mathrm{C} \text {, } \\
10 \mathrm{~g} / \mathrm{L}, \mathrm{Shaken}, \\
6 \mathrm{~min} \text { at } 5000 \mathrm{rpm} \text { and } 10 \\
\text { min at } 6000 \mathrm{rpm}\end{array}$ & $\begin{array}{l}\text { UV-Vis } \\
\text { TEM } \\
\text { XRD } \\
\text { ZP }\end{array}$ & $\begin{array}{l}\text { Size— } 6 \mathrm{~nm} \\
\text { Shape—sph. } \\
\text { Structure-FCC }\end{array}$ & $\begin{array}{l}\text { Stable for } 3 \text { months. } \\
\text { Resist growth of } E \text {. coli, } S \text {. } \\
\text { aureus and } P \text {. aeruginosa } \\
\text { Act as promising } \\
\text { anti-biofouling agent }\end{array}$ \\
\hline 95 & $\begin{array}{l}\text { Zonnoz and Salouti } \\
\text { (2011) [83] }\end{array}$ & $\begin{array}{l}\text { Aqueous cell } \\
\text { filtrate of } \\
\text { Streptomyces sp. ERI-3 }\end{array}$ & $\begin{array}{l}1 \mathrm{mM}, 48 \mathrm{hr}, 28^{\circ} \mathrm{C} . \\
\text { Dark. } \\
\text { Shaken. }\end{array}$ & $\begin{array}{l}\text { UV-Vis } \\
\text { XRD } \\
\text { TEM } \\
\text { SEM }\end{array}$ & $\begin{array}{l}\text { Size-10 - } 100 \mathrm{~nm} \\
\text { Shape-Spherical }\end{array}$ & $\begin{array}{l}\text { After } 3 \text { months, } \\
\text { nanoparticles } \\
\text { developed floret shape }\end{array}$ \\
\hline 96 & $\begin{array}{l}\text { Deepak et al. } \\
\text { (2011) [135] }\end{array}$ & $\begin{array}{l}\text { Fibrinolytic URAK } \\
\text { enzyme produced by } \\
\text { Bacillus cereus NK1 }\end{array}$ & $\begin{array}{l}1 \mathrm{mM}, 24 \mathrm{hr} \text { without } \mathrm{NaOH} \\
\text { and } 5 \mathrm{~min} \text { with } \mathrm{NaOH}, 37^{\circ} \mathrm{C} \text {, } \\
\text { URAK content: } 1 \mathrm{mg} \text {, } \\
\text { additives: } 10 \mathrm{ml} \text { of Tris-Hcl } \\
\text { buffer of } \mathrm{pH} 9\end{array}$ & $\begin{array}{l}\text { UV-Vis } \\
\text { TEM } \\
\text { XRD } \\
\text { AFM }\end{array}$ & $\begin{array}{l}\text { Size-50 - } 80 \mathrm{~nm} \\
\text { Shape-sph. } \\
\text { Structure-FCC } \\
\text { Nature-WD }\end{array}$ & $\begin{array}{l}\text { AgNP with } \\
\text { mmobilized enzyme }\end{array}$ \\
\hline 97 & $\begin{array}{l}\text { Kalishwarlal et al } \\
\text { (2010) [136] }\end{array}$ & $\begin{array}{l}\text { Brevibacterium casei } \\
\text { harvested cells }\end{array}$ & $\begin{array}{l}1 \mathrm{mM}, 24 \mathrm{hr}, 37^{\circ} \mathrm{C} \text {, } \\
1 \mathrm{~g}, \text { Shaken, } \\
30 \mathrm{~min} \text { at } 16000 \mathrm{~g}\end{array}$ & $\begin{array}{l}\text { UV-Vis } \\
\text { TEM } \\
\text { XRD } \\
\text { FTIR } \\
\text { FS }\end{array}$ & $\begin{array}{l}\text { Size-10 - } 50 \mathrm{~nm} \text {. } \\
\text { Shape-Sph. } \\
\text { Structure-FCC }\end{array}$ & $\begin{array}{l}\text { AgNP act as stable } \\
\text { anti-coagulant }\end{array}$ \\
\hline 98 & $\begin{array}{l}\text { Ganeshbabu and } \\
\text { Gunasekaran (2009) } \\
\text { [137] }\end{array}$ & $\begin{array}{l}\text { Isolated and } \\
\text { harvested Bacillus cereus } \\
\text { PGN1 cells. }\end{array}$ & $\begin{array}{l}1 \mathrm{mM}, 120 \mathrm{hr}, 37^{\circ} \mathrm{C} . \\
10 \mathrm{~g} / 100 \mathrm{ml} . \\
15 \mathrm{~min} \text { at } 15000 \mathrm{rpm} . \\
\text { Shaken. }\end{array}$ & $\begin{array}{l}\text { UV-Vis } \\
\text { FTIR } \\
\text { XRD } \\
\text { TEM }\end{array}$ & $\begin{array}{l}\text { Size-4-5 nm } \\
\text { Shape-Sph. } \\
\text { Structure-FCC. } \\
\text { Nature-MD. }\end{array}$ & $\begin{array}{l}\text { Tris Buffer }(\mathrm{pH}-7) \text { as } \\
\text { suspension media for } \\
\text { nanoparticles }\end{array}$ \\
\hline 99 & $\begin{array}{l}\text { Nanda et al (2009) } \\
\text { [138] }\end{array}$ & $\begin{array}{l}\text { Staphylococcus aureus } \\
\text { supernatant }\end{array}$ & $1 \mathrm{mM}, 5 \mathrm{~min}$ & $\begin{array}{l}\text { UV-Vis } \\
\text { AFM }\end{array}$ & $\begin{array}{l}\text { Size- } 160-180 \mathrm{~nm} \\
\text { Nature-PD. }\end{array}$ & $\begin{array}{l}\text { AgNP antibacterial action } \\
\text { against human pathogenic } \\
\text { bacteria MRSA, MRSE, S. } \\
\text { pyogenes }\end{array}$ \\
\hline 100 & $\begin{array}{l}\text { Kalimuthu et al } \\
\text { (2008) [139] }\end{array}$ & $\begin{array}{l}\text { Bacillus } \\
\text { icheniormis cells }\end{array}$ & $\begin{array}{l}1 \mathrm{mM}, 24 \mathrm{hr}, 37^{\circ} \mathrm{C} \text {, } \\
30 \text { min at } 15000 \mathrm{rpm} . \\
\text { Shaken }\end{array}$ & $\begin{array}{l}\text { UV-Vis } \\
\text { SEM } \\
\text { EDX } \\
\text { XRD }\end{array}$ & $\begin{array}{l}\text { Size- } 50 \mathrm{~nm} \\
\text { Structure-Crystal } \\
\text { Nature-WD }\end{array}$ & \\
\hline \multicolumn{7}{|c|}{ Gram negative bacteria } \\
\hline 101 & $\begin{array}{l}\text { Perni et al } \\
\text { (2013) [58] }\end{array}$ & Escherichia coli cells & $\begin{array}{l}1 \text { or } 5 \mathrm{mM}, 24 \mathrm{hr}, 30^{\circ} \mathrm{C} \text {, } \\
\text { Ratio of } \mathrm{AgNO}_{3} \text { : } \\
\text { L-cysteine = 1:5, } \\
\text { Shaken, } \\
10 \text { min at } 1851 \mathrm{~g}\end{array}$ & $\begin{array}{l}\text { UV-Vis } \\
\text { FTIR } \\
\text { TEM } \\
\text { TGA }\end{array}$ & Size $\sim \sim 5 \mathrm{~nm}$ & $\begin{array}{l}\text { Capping agent: L-cysteine, } \\
\text { Antimicrobial against } E \text {. } \\
\text { coliand S. aureus }\end{array}$ \\
\hline 102 & $\begin{array}{l}\text { Juibari et al. (2011) } \\
\text { [140] }\end{array}$ & $\begin{array}{l}\text { Ureibacillus } \\
\text { thermo sphaerius } \\
\text { supernatant }\end{array}$ & $\begin{array}{l}1-100 \mathrm{mM}, 24 \mathrm{hr}, \\
60^{\circ} \mathrm{C}-80^{\circ} \mathrm{C}, \\
\text { Dark, } 15 \mathrm{~min}(13 \mathrm{k}, \mathrm{rpm} \\
\text { Static }\end{array}$ & $\begin{array}{l}\text { UV-Vis } \\
\text { DLS } \\
\text { XRD } \\
\text { FTIR } \\
\text { TEM }\end{array}$ & $\begin{array}{l}\text { Size-10 - } 100 \mathrm{~nm} \\
\text { Shape-Sph. } \\
\text { Structure-FCC } \\
\text { Nature-PD }\end{array}$ & $\begin{array}{l}\text { Temperature around } 80^{\circ} \mathrm{C} \\
\text { stands possible because of } \\
\text { thermophilic nature of } \\
\text { bacteria }\end{array}$ \\
\hline 103 & $\begin{array}{l}\text { Gurunathan et al. } \\
\text { (2009) [141] }\end{array}$ & E. coli supernatant & $\begin{array}{l}1-10 \mathrm{mM}, 24 \mathrm{hr}, \\
20^{\circ} \mathrm{C}-90^{\circ} \mathrm{C}, \\
\mathrm{pH}: 5-12, \\
10 \text { min at } 10 \mathrm{k} \mathrm{rpm} \\
\text { Static }\end{array}$ & $\begin{array}{l}\text { UV-Vis } \\
\text { DLS } \\
\text { TEM } \\
\text { FTIR }\end{array}$ & $\begin{array}{l}\text { Size-10-90 nm } \\
\text { Shape-Sph. } \\
\text { Structure-Crystal } \\
\text { Nature-Uniform }\end{array}$ & $\begin{array}{l}\text { Nitrate medium (pH-8) is used } \\
\text { for culture. }\end{array}$ \\
\hline 104 & $\begin{array}{l}\text { Shahverdi et al } \\
\text { (2007) [59] }\end{array}$ & $\begin{array}{l}\text { K. pneumonia } \\
\text { (Enterobacteria) } \\
\text { supernatant }\end{array}$ & $1 \mathrm{mM}, 5 \mathrm{~min}$, Room temp. & $\begin{array}{l}\text { UV-Vis } \\
\text { TEM } \\
\text { EDS }\end{array}$ & $\begin{array}{l}\text { Size-Avg: } 52.25 \\
\text { nm } \\
\text { Shape-Sph. }\end{array}$ & $\begin{array}{l}\text { Nanoparticles are unstable } \\
\text { after } 5 \text { min. Addition of } \\
\text { piperitone resisted the } \\
\text { nanoparticle growth. }\end{array}$ \\
\hline \multicolumn{7}{|c|}{ Bio-polymers } \\
\hline
\end{tabular}




\section{Continued}

\begin{tabular}{|c|c|c|c|c|c|c|}
\hline 105 & $\begin{array}{l}\text { Cheng et al. } \\
\text { (2014) [142] }\end{array}$ & Chondrotin sulfate & $\begin{array}{l}1 \text { and } 6.25 \mathrm{mM} \text {, } \\
3-120 \mathrm{hr}, 25^{\circ} \mathrm{C} \text { and } 80^{\circ} \mathrm{C} \text {, } \\
0.8 \text { to } 20 \mathrm{mg} / \mathrm{l} \text {, } \\
10 \mathrm{~min} \text { at } 5000 \mathrm{~g} \text {, Stirred }\end{array}$ & $\begin{array}{l}\text { UV-Vis } \\
\text { FTIR } \\
\text { TEM } \\
\text { DLS }\end{array}$ & $\begin{array}{l}\text { Size—<20 nm } \\
\text { Shape—sph. }\end{array}$ & $\begin{array}{l}\text { Stable for } 2 \text { months, } \\
\text { Served as nano carrier for } \\
\text { drug delivery }\end{array}$ \\
\hline 106 & $\begin{array}{l}\text { Chen et al. } \\
\text { (2014) [143] }\end{array}$ & $\begin{array}{l}\text { Chitosan } \\
\text { biopolymer }\end{array}$ & & $\begin{array}{l}\text { UV-Vis } \\
\text { FTIR } \\
\text { TEM } \\
\text { DLS }\end{array}$ & $\begin{array}{l}\text { Size— } 218.4 \mathrm{~nm} \\
\text { Shape—oval and sph. } \\
\text { Nature—Ag/ } \\
\text { chitosan nano } \\
\text { hybrids }\end{array}$ & $\begin{array}{l}\text { Antimicrobial to E. coli, S. } \\
\text { choleraesuis, S. aureus and } \\
\text { B. subtilis }\end{array}$ \\
\hline 107 & $\begin{array}{l}\text { Tagad et al. } \\
\text { (2013) [80] }\end{array}$ & $\begin{array}{l}\text { Locust bean gum } \\
\text { polysaccharide. }\end{array}$ & $\begin{array}{l}1-5 \mathrm{mM}, 6 \mathrm{hr}, 60^{\circ} \mathrm{C} \text {, } \\
0.1 \text { to } 0.4(\mathrm{w} / \mathrm{v}) / 25 \mathrm{ml} \text {, } \\
\text { pH: } 4 \text { to } 12 \text {, } \\
\text { Static }\end{array}$ & $\begin{array}{l}\text { UV-Vis } \\
\text { AFM }\end{array}$ & Size-18 - $51 \mathrm{~nm}$ & $\begin{array}{l}\text { Stability: } 7 \text { months, } \\
\text { AgNP served in } \\
\text { development of } \mathrm{H}_{2} \mathrm{O}_{2} \text { sensor }\end{array}$ \\
\hline 108 & $\begin{array}{l}\text { El-Rafie et al. } \\
\text { (2013) [144] }\end{array}$ & $\begin{array}{l}\text { Crude hot water soluble } \\
\text { polysaccharide extracted } \\
\text { from different marine } \\
\text { algae }\end{array}$ & $\begin{array}{l}0.1 \mathrm{mM}, 20 \mathrm{~min}, 70^{\circ} \mathrm{C}, \\
0.3(\mathrm{mg} / \mathrm{ml}) / 1 \mathrm{ml}, \\
\text { pH: } 10.10 \mathrm{~min} \text { at } 5000 \mathrm{rpm}, \\
\text { Stirring }\end{array}$ & $\begin{array}{l}\text { UV-Vis } \\
\text { FTIR } \\
\text { TEM }\end{array}$ & $\begin{array}{l}\text { Size-7 - } 20 \mathrm{~nm} \\
\text { Shape—-sph }\end{array}$ & $\begin{array}{l}\text { Stability: } 6 \text { months, AgNP } \\
\text { treated cotton fibers } \\
\text { antibacterial to } E \text {. coli and } S . \\
\text { aureus }\end{array}$ \\
\hline 109 & $\begin{array}{l}\text { Ashraf et al. } \\
\text { (2013) [77] }\end{array}$ & $\begin{array}{l}\text { Casein milk } \\
\text { protein }\end{array}$ & $\begin{array}{l}1 \mathrm{mM}, 5-10 \mathrm{~min}, \\
50^{\circ} \mathrm{C}-60^{\circ} \mathrm{C}, 1-\mathrm{c} 10 \mathrm{ml} / 25 \mathrm{ml} \text {, } \\
\mathrm{pH}: 10-14 \text {, vigorous } \\
\text { stirring }\end{array}$ & $\begin{array}{l}\text { UV-Vis } \\
\text { FTIR } \\
\text { SEM } \\
\text { TEM } \\
\text { DLS } \\
\text { ZP }\end{array}$ & $\begin{array}{l}\text { Size- } \mathrm{pH}>7 \text { : } \\
3-18 \mathrm{~nm}, \mathrm{pH}<6 \text { : } \\
60-80 \mathrm{~nm} . \\
\text { Shape-sph. }\end{array}$ & $\begin{array}{l}\text { Cytotoxocity and cellular } \\
\text { uptake of AgNP was studied. }\end{array}$ \\
\hline 110 & $\begin{array}{l}\text { Dehnavi et al. } \\
\text { (2013) [78] }\end{array}$ & Fructose & $\begin{array}{l}10-100 \mathrm{ppm}, 11-100 \mathrm{~min} \text {, } \\
55^{\circ} \mathrm{C}-95^{\circ} \mathrm{C}, 1(\mathrm{~g} / \mathrm{L}) / 9.35 \mathrm{ml} \text {, } \\
\text { Other contents: Diammonium } \\
\text { hydrogen citrate, } 1 \mathrm{M} \\
\text { ammonium solution, } \\
\text { pH: } 8.5 \text { to } 11.5 \text {, stirring }\end{array}$ & $\begin{array}{l}\text { UV-Vis } \\
\text { FE-SEM } \\
\text { TEM } \\
\text { XRD } \\
\text { DLS }\end{array}$ & $\begin{array}{l}\text { Size-36 nm } \\
\text { Shape-sph. } \\
\text { Structure- } \\
\text { crystalline } \\
\text { Nature-WD and } \\
\text { homogenous }\end{array}$ & $\begin{array}{l}\text { Stability for } 1 \text { month, } \\
\text { Antibacterial to E. coli and } S \text {. } \\
\text { aureus }\end{array}$ \\
\hline 111 & $\begin{array}{l}\text { Ortega-arroyo et } \\
\text { al. } \\
\text { (2013) [60] }\end{array}$ & D-glucose & $\begin{array}{l}0.13 \text { to } 0.97 \mathrm{M}, 1 \mathrm{~min}, \\
26^{\circ} \mathrm{C}-94^{\circ} \mathrm{C} \text {, } \\
150 \mu \mathrm{L}(0.1 \mathrm{M}) / 100 \mu \mathrm{L}, \\
\text { Capping agent-6ml of } 1.7 \\
\text { wt } \% \text {, pH: } 7 \text { to } 13 \text {, } \\
\text { Stirred }\end{array}$ & $\begin{array}{l}\text { UV-Vis } \\
\text { TEM } \\
\text { XRD } \\
\text { RS }\end{array}$ & $\begin{array}{l}\text { Size-2 - } 24 \mathrm{~nm} \\
\text { Shape-sph and } \\
\text { polyhedral } \\
\text { Structure-FCC } \\
\text { Nature- } \\
\text { homogenous WD }\end{array}$ & $\begin{array}{l}\text { Smaller particle range of } \\
\text { silver nanoparticles are } \\
\text { observed at } 0.55 \mathrm{M} \text { D-glucose, } \\
\text { pH- } 11 \text { and } \\
\text { temperature }>70^{\circ} \mathrm{C} \text {. }\end{array}$ \\
\hline 112 & $\begin{array}{l}\text { Lu et al. } \\
\text { (2012) [145] }\end{array}$ & Egg white extract & $\begin{array}{l}10 \mathrm{mM}, 72 \mathrm{hr} \text {, room temp. } \\
1 \mathrm{ml} / 2 \mathrm{ml} \text {, Vigorous stirring, } \\
15 \mathrm{~min}, 15 \mathrm{k} \mathrm{rpm}\end{array}$ & $\begin{array}{l}\text { UV-Vis } \\
\text { FTIR } \\
\text { TEM } \\
\text { DLS }\end{array}$ & $\begin{array}{l}\text { Size— } 20 \mathrm{~nm} \\
\text { Shape—sph } \\
\text { Structure-Cryst }\end{array}$ & $\begin{array}{l}\text { Silver nanoparticle conjugate } \\
\text { is used in cancer radiation } \\
\text { therapy. }\end{array}$ \\
\hline 113 & $\begin{array}{l}\text { Guidelli et al. } \\
\text { (2012) [146] }\end{array}$ & DL-Alanine & $\begin{array}{l}\text { Ag/alanine ratio (\%): } 0.045 \\
\text { to } 0.36,40 \mathrm{~min}, 100^{\circ} \mathrm{C} \text {. } \\
\text { vigorous } \\
\text { stirring. }\end{array}$ & $\begin{array}{l}\text { UV-Vis } \\
\text { FTIR } \\
\text { TEM } \\
\text { XRD }\end{array}$ & $\begin{array}{l}\text { Size- } 7.5 \mathrm{~nm} \\
\text { Shape-sph. } \\
\text { Structure-FCC }\end{array}$ & $\begin{array}{l}\text { Nanoparticle stands applicable } \\
\text { for ESR-Dosimetry. }\end{array}$ \\
\hline 114 & $\begin{array}{l}\text { Tanvir et al. } \\
\text { (2012) [147] }\end{array}$ & Co-enzyme ( $\beta$-NADPH) & $\begin{array}{l}0.31-10 \mathrm{mM}, 20^{\circ} \mathrm{C} . \\
1: 1 \text { to } 3: 1 . \\
\text { Stirring, } \\
30 \mathrm{~min} \text { at } 15000 \mathrm{rpm}\end{array}$ & $\begin{array}{l}\text { UV-Vis } \\
\text { TEM } \\
\text { XRD } \\
\text { DLS } \\
\text { ZP } \\
\text { EDAX }\end{array}$ & $\begin{array}{l}\text { Size-20.77 } \pm 0.67 \\
\text { nm } \\
\text { Shape-sph. } \\
\text { Structure-FCC } \\
\text { Nature-narrow and } \\
\text { MD }\end{array}$ & $\begin{array}{l}\text { Stabile for } 2 \text { months, } \\
\text { The reagent used for the } \\
\text { synthesis of nanoparticles can } \\
\text { be regenerated. }\end{array}$ \\
\hline 115 & $\begin{array}{l}\text { Bankura et al. } \\
\text { (2012) [148] }\end{array}$ & Dextran & $\begin{array}{l}0.01 \mathrm{M} \text {, room temp. } \\
\text { 5\%, Additive: } 0.4 \mathrm{ml} \text { of } \\
0.001 \mathrm{M} \mathrm{NaOH} \text {, } \\
\text { static }\end{array}$ & $\begin{array}{l}\text { UV-Vis } \\
\text { TEM } \\
\text { XRD } \\
\text { EDAX } \\
\text { AFM } \\
\text { UV-Vis }\end{array}$ & $\begin{array}{l}\text { Size-5 - } 60 \mathrm{~nm} \\
\text { Shape-sph. } \\
\text { Structure-FCC } \\
\text { Nature-WD }\end{array}$ & $\begin{array}{l}\text { Stable for } 1 \text { months, } \\
\text { Antimicrobial to B. subtilis, } B \text {. } \\
\text { cereus, E. coli, S. aureus, } P \text {. } \\
\text { aeruginosa }\end{array}$ \\
\hline 116 & $\begin{array}{l}\text { Sasikala et al. } \\
\text { (2012) [149] }\end{array}$ & Soyabean protein & $\begin{array}{l}1 \mathrm{mM}, 24 \mathrm{hr} \text {, room temp. } \\
1 \mathrm{~g} / 100 \mathrm{ml} \text {, } \\
10 \mathrm{~min} \text { at } 10000 \mathrm{rpm}, \\
\text { Static }\end{array}$ & $\begin{array}{l}\text { FTIR } \\
\text { HR-SEM } \\
\text { HRTEM } \\
\text { XRD } \\
\text { EDAX }\end{array}$ & $\begin{array}{l}\text { Size-7 - } 29 \mathrm{~nm} \\
\text { Shape-sph. } \\
\text { Structure-FCC } \\
\text { Nature-WD }\end{array}$ & $\begin{array}{l}\text { Protein of } 51 \mathrm{kDa} \text { was } \\
\text { responsible for the formation } \\
\text { of AgNP formation. }\end{array}$ \\
\hline 117 & $\begin{array}{l}\text { Morales-Sanchez } \\
\text { et al. [61] }\end{array}$ & Albumin & $\begin{array}{l}30 \mathrm{mM}, 24 \mathrm{~min} \text {, room temp. } \\
\text { Additive: Ammonium } \\
\text { hydroxide (pH: 11), Stirred }\end{array}$ & $\begin{array}{l}\text { UV-Vis } \\
\text { TEM } \\
\text { TGA } \\
\text { DLS }\end{array}$ & $\begin{array}{l}\text { Size— } 26 \mathrm{~nm} \\
\text { Shape—sph. }\end{array}$ & Stable for 6 months \\
\hline 118 & $\begin{array}{l}\text { El-rafie et al. } \\
\text { (2011) [81] }\end{array}$ & Hydropropyl starch & $\begin{array}{l}100-750 \mathrm{ppm}, 15-90 \mathrm{~min} \text {, } \\
30^{\circ} \mathrm{C}-90^{\circ} \mathrm{C}, 9 \mathrm{~g} / \mathrm{l} \text { with } 0.84 \\
\text { molar substitutions, } \\
\text { pH: } 2 \text { - } 12 \text {, Stirring }\end{array}$ & $\begin{array}{l}\text { UV-Vis } \\
\text { TEM }\end{array}$ & Size-6-8 nm & $\begin{array}{l}\text { Stable for } 6 \text { months, } \\
\text { More reduction at higher } \mathrm{pH} \text {, } \\
\text { rate increased rate with temp; } \\
\text { particle aggregation with time }\end{array}$ \\
\hline 119 & $\begin{array}{l}\text { Philip } \\
\text { (2010) [21] }\end{array}$ & Honey & $\begin{array}{l}1 \mathrm{mM}, 1 \mathrm{~min}, 15 \mathrm{ml} / 20 \mathrm{ml} \text {, } \\
\text { pH: } 6.5 \text { - 8.5, } \\
\text { Stirred }\end{array}$ & $\begin{array}{l}\text { UV-Vis } \\
\text { FTIR } \\
\text { HR-TEM } \\
\text { XRD }\end{array}$ & $\begin{array}{l}\text { Size-4 nm } \\
\text { Shape-sph. } \\
\text { Structure-FCC } \\
\text { Nature-MD }\end{array}$ & $\begin{array}{l}\text { Stabile for } 6 \text { months, } \\
\text { NaOH is added for } \mathrm{pH} \\
\text { adjustment }\end{array}$ \\
\hline 120 & $\begin{array}{l}\text { Kora et al. } \\
(2010)[62]\end{array}$ & $\begin{array}{l}\text { Gum kondagogu } \\
\text { (Cochlospermum } \\
\text { gossypium) }\end{array}$ & $\begin{array}{l}1-5 \mathrm{mM}, 10-60 \mathrm{~min}, \\
121^{\circ} \mathrm{C}, 15 \mathrm{psi}, \\
0.1-0.5(\mathrm{w} / \mathrm{v}), \\
\text { gum mean particle size: } \\
30-300 \mu \mathrm{m}, \\
\text { Static }\end{array}$ & $\begin{array}{l}\text { UV-Vis } \\
\text { TEM } \\
\text { XRD } \\
\text { TGA }\end{array}$ & $\begin{array}{l}1 \mathrm{mM} \mathrm{AgNO} \text {, }(0.1) \\
\text { and (0.5) } \mathrm{w} / \mathrm{v} \% \\
\text { gum: Size-30 } \\
\text { min-(55) and } \\
(11.2) \mathrm{nm} \text {; } \\
60 \mathrm{~min}-(18.9) \text { and } \\
\text { (4.5) nm } \\
\text { Shape-(R, hex) and } \\
\text { (sph). } \\
\text { Structure-FCC } \\
\text { Nature-PD, WD }\end{array}$ & $\begin{array}{l}\text { Anti-bacterial to } S \text {. aureus, E. } \\
\text { coli, and P. aeruginosa }\end{array}$ \\
\hline
\end{tabular}

Note: DLS—Dynamic light scattering, EDAX/EDS Energy Dispersive X-ray Analysis/Energy Dispersive Spectroscopy; FTIR-Fourier transform infrared spectroscopy, HRTEM-High Resolution Transmission Electron Microscopy; SEM-Scanning Electron Microscopy, TGA-Thermogravimetric analysis, UV-Vis—Ultra violet-visible spectroscopy; XRD—X Ray Diffraction, DEC—decahedral, sph—spherical, Tri-Triangular, R— Rod, Hex-Hexagonal, PD—Polydispersed, MD—monodispersed, WD—Well Dispersed, Cryst—Crystalline. 
[32] [62] [75] [104] [115] [148]. In the Well diffusion method instead of using discs, small disc shaped pits are created on the agar plate for filling the test solution. In both the techniques, the microbe inoculated plates are incubated under standard condition for the formation of clear inhibition zone. The inhibition zone diameter around the disc or well, directly relates the effects of AgNPs on the chosen microbe.

\subsubsection{Minimum Inhibitory Concentration (MIC)/Minimum Bactericidal Concentration (MBC)}

The MIC is defined as the minimum concentration of the analyte which inhibit $100 \%$ visible growth of the targeted microbe after 24 hours. The MIC is determined by monitoring growth of bacteria in culture tubes inoculated with the same amount of bacterial culture but increasing concentration of AgNPs in the growth medium. The minimum concentration of AgNP which checks growth of bacteria is called the minimum inhibitory concentration. For the determination of MBC, fixed AgNP concentration greater than MIC value is added to the nutrient mediums containing increasing bacterial inoculum and bacterial growth is monitored, using UV-Vis spectroscopy or plate analyzer, for change in the optical density of the samples [58] [134] [142]. The broth dilution test is also used to conduct MIC and MBC analysis, in which the results after experimentation are compared with a standard data [96] [98].

\subsubsection{Analysis of SEM and TEM Micrographs}

The SEM and TEM analyses have been used to monitor changes in the morphology of the bacterial cell before and after treatment with "AgNPs"; The visible alterations in the cell shape and perforations in the cell wall have been reported and used as indicator of the antimicrobial action of AgNPs by several workers [45] [134] [142].

\subsection{Antibacterial Action}

The AgNPs have potent antibacterial action against gram positive bacteria, Lactobacillus fermentum [134], Streptomyces sp. [83]. Bacillus cereus [135] Brevibacterium casei [136], S. aureus [138] B. licheniromis [139], and gram negative bacteria, E. coli [58] Entrobacteria [59] and Ureibacillus thermo sphaerius [140]. The antibacterial action of AgNPs on gram positive and gram negative bacterial strains is not the same but competes one over the other. There are contradictory reports regarding antibacterial action against gram positive and gram negative bacteria. According to some researchers the gram negative bacteria are reported to be more sensitive to AgNPs compared to gram positive bacteria [32] [78] [111] [134] whereas reverse results were observed by other researchers [62] [75] [76] [98]. The reported differential sensitivity of both the bacterial species could be attributed to the difference in structural characteristics of the bacterial species [62] [111] as well as shape and size of AgNP, bacterial inoculum size, exposure time and nutrient medium used during analysis of antibacterial action [98].

The anti-bacterial action of AgNPs is quite complex and not well studied. Its mechanism is onlytentatively explained. The antimicrobial action of AgNPs can be categorized in two types: the inhibitory action and bactericidal action. In the former strategy bacterial cells are not killed but their division is prevented whereas in the later bacterial cells will die due to the action of AgNP [58]. The antibacterial action mechanism of AgNP is summarized in Figure 4. The graphical presentation shown in Figure 4 is the result of bacterial growth loaded with AgNPs synthesized from different green sources. Probable mechanism leading the differential behavior in the cases "a" to "e" is shown on the right hand part. The reason behind the bacterial cells resuming their growth after certain period of inhibitory action in cases "b", "c", "d" respectively was assumed to due to the unaffected cells, which in turn promote the growth (figure shown in inset). On the other hand a complete inhibition/bactericidal effect as in the case "e" is attributed to the complete death of cells. A shift from inhibitory action to nearly bactericidal action was observed with an increase in concentration of AgNPs loading [78] [134]. The experimental support in the form of morphological changes and perforations in cell wall has been presented as shown in Figure 5. The mechanism behind the bactericidal action of AgNP was illustrated by release of $\mathrm{Ag}^{+}$ ions, which serves as reservoirs for anti-microbial action [111]. The $\mathrm{Ag}^{+}$cations produced interacts with the negative charge on the cell wall and affects the membrane permeability. The nano-silver cations which have greater affinity towards sulphur and phosphorus containing compounds present in the outer membrane, respiratory enzymes, proteins and DNA, penetrate through the cell wall and plasma membrane by destabilizing them and cause protein denaturation by dissipating proton motive force, respiratory inhibition, intracellular ATP depletion 


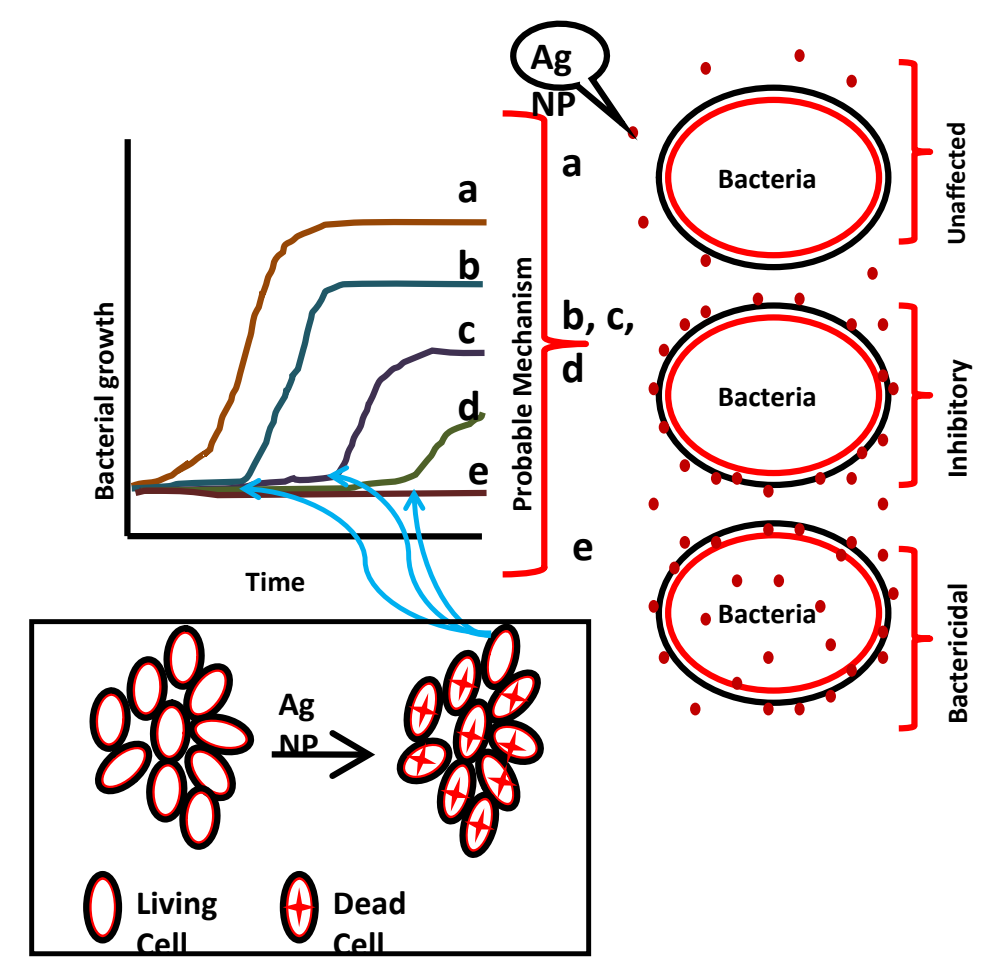

Figure 4. Mechanism of antibacterial action of AgNPs.

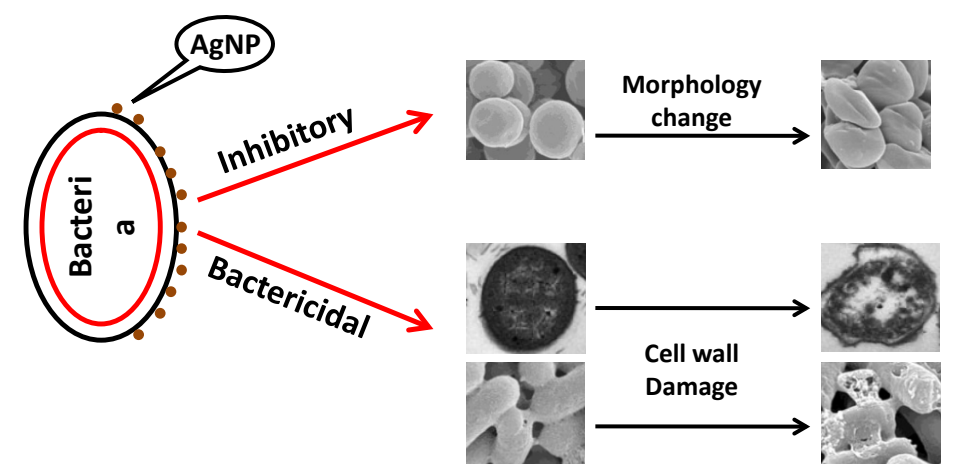

Figure 5. Morphological change and cell wall damage of bacterial cell.

and DNA damage. The above stated mechanism is in agreement with the reports of many authors [64] [72] [75] [78] [95] [98].

\subsection{Anti-Fungal Action}

The AgNPs exhibited antifungal action against various fungi [50] [98]. Actual mechanism behind the antifungal activity is not fully. The disrupting the structure of the cell membrane by destructing the membrane integrity, thereby the inhibition of the budding process has been attributed to be responsible for the antifungal action of AgNPs against C. albanicans species [150]. The shape of the AgNPs has a significant effect on the anti-microbial activity [151]

\subsection{Anti-Parasitic Action}

The AgNPs have been found to be effective larvicidal agents against dengue vector Aedes aegypt [96], and $\mathrm{Cu}$ lex quinquefasciatus [39], filariasis vector C. quinquefasciatus [120] and malarial vector A. subpictus [70], Aedes aegypti [116], A. subpictu [120] and other parasites [36] [152]. No attempt has been made to propose a 
proper mechanism for anti-parasitic action of AgNPs. Denaturation of sulfur containing proteins and phosphorus containing DNA by AgNPs, leading to denaturation of organelles and enzymes is believed to be responsible for the larvicidal activity [117].

\subsection{Anti-Fouling Action}

The AgNPs synthesized from Rhizopus oryzae fungal species have been used for treating contaminated water and adsorption of pesticides [76] and that from Lactobacillus fermentum cells have been used as anti-bio fouling agent [134]. The AgNPs are being used to treat many environmental concerns like; air disinfection, water disinfection, ground water and biological water disinfection and surface disinfection [153].

\subsection{Other Applications}

There have been several reports on the use of AgNPs in the field of medicine. The AgNPs have been used as therapeutic agents [97], as glyconano sensors for disease diagnosis [63] and as nano carriers for drugs delivery [142]. Reports are also available on the use of AgNPs in radiation therapy [145], in $\mathrm{H}_{2} \mathrm{O}_{2}$ sensor [80], in ESRDosimetry [146], as heavy metal ion sensors [110] and as catalyst for reduction of dyes such as methylene blue [31].

\section{Conclusion}

Sufficient volume of published literature is available on the synthesis of AgNPs through green routes. Among plants, angiosperm species has been widely used in comparison with the other sources. Several characterizations methods and techniques have been used for AgNPs synthesis and confirmation. The AgNPs synthesized using biological reducing and capping agents have shown wide variation in shape and size. Among applications, the anti-microbial action of AgNPs has been widely studied. Various methods used to carry out antibacterial study and elucidate mechanism of anti-microbial have been developed. The results, however, are conflicting and there is a need for more work to resolve this issue. The potential of AgNPs for their use as drug carriers in cancer therapy, as biosensors for metabolites and pollutants, as catalyst etc. is quite high and requires intensive and integrated research activity for harnessing it.

\section{Acknowledgements}

One of the Authors (SNU) is grateful to the Department of Atomic Energy, GoI, Mumbai for the award of Raja Ramanna fellowship. The financial support to DDG in the form of Dr DS Kothari Postdoc fellowship from the UGC, New Delhi is gratefully acknowledged. Authors are also grateful to Head of the Department of Chemical Engineering and Technology, IIT (BHU) for providing necessary encouragement and facilities.

\section{References}

[1] Mody, V.V., Siwale, R., Singh, A. and Mody H.R. (2010) Introduction to Metallic Nanoparticles. Journal of Pharmacy and Bioallied Sciences, 2, 282-289. http://dx.doi.org/10.4103/0975-7406.72127

[2] Sharma. V.K., Yngard, R.A. and Lin, Y. (2009) Silver Nanoparticles: Green Synthesis and Their Antimicrobial Activities. Advances in Colloid and Interface Science, 145, 83-96. http://dx.doi.org/10.1016/j.cis.2008.09.002

[3] Grier, N. (1968) Silver and Its Compounds. In: Block, S.S., Ed., Disinfection, Sterilization and Preservation, Lee and Febiger, Philadelphia, 375-398.

[4] Hill, W.R. and Pillsbury, D.M. (1939) Argyria—The Pharmacology of Silver. Williams and Williams, Baltimore.

[5] Galib, B.M., Mashru, M., Jagtap, C., Patgiri, B.J. and Prajapati, P.K. (2011) Therapeutic Potentials of Metals in Ancient India: A Review through Charaka Samhita. Journal of Ayurveda and Integrative Medicine, 2, 55-63. http://dx.doi.org/10.4103/0975-9476.82523

[6] Chaloupka, K., Malam, Y. and Seifalian, A.M. (2010) Nanosilver as a New Generation of Nanoproduct in Biomedical Applications. Trends in Bioethanology, 28, 580-588.

[7] Prow, T.W., Grice, J.E., Lin, L.L., Faye, R., Butler, M., Becker, W., Wurm, E.M.T., Yoong, C., Robertson, T.A., Soyer, H.P. and Roberts, M.S. (2011) Nanoparticles and Microparticles for Skin Drug Delivery. Advanced Drug Delivery Reviews, 63, 470-491. http://dx.doi.org/10.1016/j.addr.2011.01.012 
[8] Dankovich, T.A. and Gray, D.G. (2011) Bactericidal Paper Impregnated with Silver Nanoparticles for Point-of-Use Water Treatment. Environmental Science \& Technology, 45, 1992-1998. http://dx.doi.org/10.1021/es103302t

[9] Nair, R., Varghese, S.H., Nair. B.G., Maekawa. T., Yoshida, Y. and Sakthi Kumar, D. (2010) Nanoparticulate Material Delivery to Plants. Plant Science, 179, 154-163. http://dx.doi.org/10.1016/j.plantsci.2010.04.012

[10] Park, K., Seo, D. and Lee, J. (2008) Conductivity of Silver Paste Prepared from Nanoparticles. Colloids and Surfaces A, 313, 351. http://dx.doi.org/10.1016/j.colsurfa.2007.04.147

[11] Khan, Z., Al-Thabaiti, S.A., Obaid, A.Y. and Al-Youbi, A.O. (2011) Preparation and Characterization of Silver Nanoparticles by Chemical Reduction Method. Colloids and Surfaces B: Biointerfaces, 82, 513-517. http://dx.doi.org/10.1016/j.colsurfb.2010.10.008

[12] Chen, P., Song, L.Y. and Liu, Y.K. (2007) Synthesis of Silver Nanoparticles by Gamma-Ray Irradiation in Acetic Water Solution Containing Chitosan. Radiation Physics and Chemistry, 76, 1165-1168. http://dx.doi.org/10.1016/j.radphyschem.2006.11.012

[13] Zhang, W.Z., Qiao, X.L. and Chen, J.G. (2006) Synthesis and Characterization of Silver Nanoparticles in AOT Micro-Emulsion System. Chemical Physics, 300, 495-500. http://dx.doi.org/10.1016/j.chemphys.2006.09.029

[14] Reicha, F.M., Sarhan, A., Abdel-Hamid, M.I. and El-Sherbiny, I.M. (2012) Preparationof Silver Nanoparticles in the Presence of Chitosan by Electrochemical Method. Carbohydrate Polymers, 89, 236-244. http://dx.doi.org/10.1016/j.carbpol.2012.03.002

[15] Abid, J.P., Wark, A.W., Brevetm, P.F. and Girault, H.H. (2002) Preparation of Silver Nanoparticles in Solution from a Silver Salt by Laser Irradiation. Chemical Communications, 7, 792-793. http://dx.doi.org/10.1039/b200272h

[16] Yang, J. and Pan, J. (2012) Hydrothermal Synthesis of Silver Nanoparticles by Sodium Alginate and Their Applications in Surface-Enhanced Raman Scattering and Catalysis. Acta Materialia, 60, 4753-4758. http://dx.doi.org/10.1016/j.actamat.2012.05.037

[17] Khan, A., El-Toni, A.M., Alrokayan, S., Alsalhi, M., Alhoshan, M. and Aldwayyan, A.S. (2011) Microwave-Assisted Synthesis of Silver Nanoparticles Using Poly-N Isopropyl Acrylamide/Acrylic Acid Microgel Particles. Colloids and Surfaces A: Physicochemical and Engineering Aspects, 377, 356-360. http://dx.doi.org/10.1016/j.colsurfa.2011.01.042

[18] Alarcon, E.I., Udekwu, K., Skog, M., Pacioni, N.L., Stamplecoskie, K.G., González-Béjar, M., et al. (2012) The Biocompatibility and Antibacterial Properties of Collagen-Stabilized, Photochemically Prepared Silver Nanoparticles. Biomaterials, 33, 4947-4956. http://dx.doi.org/10.1016/j.biomaterials.2012.03.033

[19] Song, J.Y. and Kim, B.S. (2009) Rapid Biological Synthesis of Silver Nanoparticles Using Plant Leaf Extracts. Bioprocess and Biosystems Engineering, 32, 79-84. http://dx.doi.org/10.1007/s00449-008-0224-6

[20] Huang, H. and Yang, X. (2004) Synthesis of Polysaccharide-Stabilized Gold and Silver Nanoparticles: A Green Method. Carbohydrate Research, 339, 2627-2631. http://dx.doi.org/10.1016/j.carres.2004.08.005

[21] Philip, D. (2010) Honey Mediated Green Synthesis of Silver Nanoparticles. Spectrochimica Acta Part A: Molecular and Biomolecular Spectroscopy, 75, 1078-1081. http://dx.doi.org/10.1016/j.saa.2009.12.058

[22] Philip, D. (2010) Rapid Green Synthesis of Spherical Gold Nanoparticles Using Mangifera indica Leaf. Spectrochimica Acta Part A: Molecular and Biomolecular Spectroscopy, 77, 807-810. http://dx.doi.org/10.1016/j.saa.2010.08.008

[23] Mittal, A.K., Chisti, Y. and Banerjee, U.C. (2013) Synthesis of Metallic Nanoparticles Using Plant Extracts. Biotechnology Advances, 31, 346-356. http://dx.doi.org/10.1016/j.biotechadv.2013.01.003

[24] Prabhu, S. and Polusu, E.K. (2012) Silver Nanoparticles: Mechanism of Antimicrobial Action, Synthesis, Medical Applications and Toxicity Affects. International Nano Letters, 2, 32. http://dx.doi.org/10.1186/2228-5326-2-32

[25] Gopinath, S.M., Saha, N.S., John, V.J., Khanum, N.S., Ganesh, S. and Patil, G.M.A. (2013) Biological Synthesis, Characterization and Application of Silver Nanoparticles. International Journal of Pharmaceutical Applications, 4, $19-28$.

[26] Geoprincy, G., Srri, B.N.V., Poonguzhali, U., Gandhi, N.N. and Renganthan, S.A. (2013) Review on Green Synthesis of Silver Nanoparticles. Asian Journal of Pharmaceutical and Clinical Research, 6, 8-12.

[27] Kaler, A., Patel, N. and Banerjee, U.C. (2010) Green Synthesis of Silver Nanoparticles. Current Research and Information on Pharmaceutical Science, 11, 68-71.

[28] Vijaykumar, P.P.N., Pammi, S.V.N., Kollu, P., Satyanarayana, K.V.V. and Shameem, U. (2014) Green Synthesis and Characterization of Silver Nanoparticles Using Boerhaavia diffusa Plant Extract and Their Antibacterial Activity. Industrial Crops and Products, 52, 562-566. http://dx.doi.org/10.1016/j.indcrop.2013.10.050

[29] Anuj, S.A. and Ishnava, K.B. (2013) Plant Mediated Synthesis of Silver Nanoparticles Using Dried Stem Powder of Tinospora cordifolia, Its Antibacterial Activity and Its Comparison with Antibiotics. International Journal of Pharmacy and Biological Sciences, 4, 849-863.

[30] Chandran, S.P., Chaudhary, M., Pasricha, R., Ahmad, A. and Sastry, M. (2006) Synthesis of Gold Nanotriangles and 
Silver Nanoparticles Using Aloe vera Plant Extract. Biotechnology Progress, 22, 577-583. http://dx.doi.org/10.1021/bp0501423

[31] Edison, T.J.I. and Sethuraman, M.G. (2012) Instant Green Synthesis of Silver Nanoparticles Using Terminalia chebula Fruit Extract and Evaluation of Their Catalytic Activity on Reduction of Methylene Blue. Process Biochemistry, 47, 1351-1357. http://dx.doi.org/10.1016/j.procbio.2012.04.025

[32] Mukunthan, K.S., Elumalai, E.K., Patel, E.N. and Murty, V.R. (2011) Catharanthus roseus: A Natural Source for Synthesis of Silver Nanoparticles. Asian Pacific Journal of Tropical Biomedicine, 1, 270-274. http://dx.doi.org/10.1016/S2221-1691(11)60041-5

[33] Patil, R.S., Kokate, M.R. and Kolekar, S.S. (2012) Bioinspired Synthesis of Highly Stabilized Silver Nanoparticles Using Ocimum tenuiflorum Leaf Extract and Their Antibacterial Activity. Spectrochimica Acta Part A: Molecular and Biomolecular Spectroscopy, 91, 234-238. http://dx.doi.org/10.1016/j.saa.2012.02.009

[34] Tripathi, A., Chandrasekaran, N., Raichur, A.M. and Mukherjee, A. (2009) Antibacterial Applications of Silver Nanoparticles Synthesized by Aqueous Extract of Azadirachta indica (Neem) Leaves. Journal of Biomedical Nanotechnology, 5, 93-98. http://dx.doi.org/10.1166/jbn.2009.038

[35] Ankamwar, B., Damle, C., Ahmad, A. and Sastry, M. (2005) Biosynthesis of Gold and Silver Nanoparticles Using Emblica officinalis Fruit Extract, Their Phase Transfer and Transmetallation in an Organic Solution. Journal of Nanoscience and Nanotechnology, 5, 1665-1671. http://dx.doi.org/10.1166/jnn.2005.184

[36] Roopan, S.M., Rohit, Madhumitha, G., Rahuman, A.A., Kamraj, C., Bharathi, A. and Surendra, T.V. (2013) Low-Cost and Eco-Friendly Phyto-Synthesis of Silver Nanoparticles Using Coos nucifera Coir Extract and Its Larvicidal Activity.Industrial Crops and Products, 43, 631-635. http://dx.doi.org/10.1016/j.indcrop.2012.08.013

[37] Shukla, V.K., Singh, R.P. and Pandey, A.C. (2010) Black Pepper Assisted Biomimetic Synthesis of Silver Nanoparticles. Journal of Alloys and Compounds, 507, L13-L16. http://dx.doi.org/10.1016/j.jallcom.2010.07.156

[38] Satishkumar, M., Sneha, K., Won, S.W., Cho, C.W., Kim, S. and Yun, Y.S. (2009)Cinnamon zeylancium Bark Extract and Powder Mediated Green Synthesis of Nano-Crystalline Silver Particles and Its Antibacterial Activity. Colloids and Surfaces B: Biointerfaces, 73, 332-338. http://dx.doi.org/10.1016/j.colsurfb.2009.06.005

[39] Mondal, N.K., Chaudhury, A., Mukhopadhya, P., Chatterjee, S., Das, K. and Datta, J.K. (2014) Green Synthesis of Silver Nanoparticles and Its Application for Mosquito Control. Asian Pacific Journal of Tropical Disease, 4, S204-S210. http://dx.doi.org/10.1016/s2222-1808(14)60440-0

[40] Rao, P., Chandraprasad, M.S., Lakshmi, Y.N., Rao, J., Aishwarya, P. and Shetty, S. (2014) Biosynthesis of Silver Nanoparticles Using Lemon Extract and Its Antibacterial Activity. International Journal of Multidisciplinary and Current Research, 2, 165-169.

[41] Elumalai, E.K., Kayalvizhi, K. and Silvan, S. (2014) Coconut Water Assisted Green Synthesis of Silver Nanoparticles. Journal of Pharmacy \& Bioallied Sciences, 6, 241-245. http://dx.doi.org/10.4103/0975-7406.142953

[42] Shankar, S.S., Ahmad, A. and Sastry, M. (2003) Geranium Leaf Assisted Biosynthesis of Silver Nanoparticles. Biotechnology Progress, 19, 1627-1631. http://dx.doi.org/10.1021/bp034070w

[43] Sadeghi, B., Rostami, A. and Momei, S.S. (2015) Facile Green Synthesis of Silver Nanoparticles Using Seed Aqueous Extract of Pistacia atlantica and Its Antibacterial Activity.Spectrochimica Acta Part A: Molecular and Biomolecular Spectroscopy, 134, 326-332. http://dx.doi.org/10.1016/j.saa.2014.05.078

[44] Sadeghi, B. and Gholamhoseinpoor, F. (2015) A Study on Stability and Green Synthesis of Silver Nanoparticles Using Ziziphora tenuior ( $\mathrm{Zt}$ ) Extract at Room Temperature. Spectrochimica Acta Part A: Molecular and Biomolecular Spectroscopy, 134, 310-315. http://dx.doi.org/10.1016/j.saa.2014.06.046

[45] Rahimi-Nasrabadi, M., Pourmortazavi, S.M., Shandiz, S.A.S., Ahmadi, F. and Batooli, H. (2014)Green Synthesis of Silver Nanoparticles Using Eucalyptus leucoxylon Leaves Extract and Evaluating the Antioxidant Activities of the Extract. Natural Product Research, 28, 1964-1969. http://dx.doi.org/10.1080/14786419.2014.918124

[46] Shafaghat, A. (2014) Synthesis and Characterization of Silver Nanoparticles by Phytosynthesis Method and Their Biological Activity. Synthesis and Reactivity in Inorganic, Metal-Organic, and Nano-Metal Chemistry, 45, 381-387. http://dx.doi.org/10.1080/15533174.2013.819900

[47] Kulkarni, A.P., Srivastava, A.A., Nagalgaon, R.K. and Zunjarrao, R.S. (2012) Phytofabrication of Silver Nanoparticles from a Novel Plant Source and Its Application. International Journal of Biological \& Pharmaceutical Research, 3 , 417-421.

[48] Logeswari, P., Silambarasan, J. and Abraham, J. (2015) Synthesis of Silver Nanoparticles Using Plants Extract and Analysis of Their Antimicrobial Property. Journal of Saudi Chemical Society, 19, 311-317. http://dx.doi.org/10.1016/j.jscs.2012.04.007

[49] Rajesh, S., Raja, D.P., Rathi, J.M. and Sahayaraj, K. (2012) Biosynthesis of Silver Nanoparticles Using Ulva fasciata (Delile) Ethyl Acetate Extract and Its Activity against Xanthomonas campestris pv. Malvacearum. Journal of Biopesti- 
cides, 5, 119-128.

[50] Bankar, A., Joshi, B., Kumar, A.R. and Zinjarde, S. (2010) Banana Peel Extract Mediated Novel Route or the Synthesis of Silver Nanoparticles. Colloids and Surfaces A: Physicochemical and Engineering Aspects, 368, 58-63. http://dx.doi.org/10.1016/j.colsurfa.2010.07.024

[51] Patete, J.M., Peng, X., Koenigsmann, C., Xu, Y., Karn, B. and Wong, S.S. (2011) Viable Methods or the Synthesis of High Quality Nanostructures. Green Chemistry, 13, 482-519. http://dx.doi.org/10.1039/c0gc00516a

[52] Mukherjee, P., Ahmad, A., Mandal, D.D., Senapati, S., Sainkar, S.R., Khan, M.I., Parishcha, R., Ajaykumar, P.V., Alam, M., Kumar, R. and Sastry, M. (2001) Fungus-Mediated Synthesis of Silver Nanoparticles and Their Immobilization in the Mycelial Matrix: A Novel Biological Approach to Nanoparticle Synthesis. Nano Letters, 1, 515-519. http://dx.doi.org/10.1021/nl0155274

[53] Ajitha, B., Redd, Y.A.K. and Reddy, P.S. (2014) Biosynthesis of Silver Nanoparticles Using Plectranthus amboinicus Leaf Extract and Its Antimicrobial Activity. Spectrochimica Acta Part A: Molecular and Biomolecular Spectroscopy, 128, 257-262. http://dx.doi.org/10.1016/j.saa.2014.02.105

[54] Bhainsa, K.C. and D’souza, S.F. (2006) Extracellular Biosynthesis of Silver Nanoparticles Using the Fungus Aspergillus fumigates. Colloids and Surfaces B: Biointerfaces, 47, 160-164. http://dx.doi.org/10.1016/j.colsurfb.2005.11.026

[55] Ahmad, A., Mukherjee, P., Senapati, S., Mandal, D., Kham, M.I., Kumar, R. and Sastry, M. (2003) Extracellular Biosynthesis of Silver Nanoparticles Using the Fungus Fusarium oxysporum. Colloids and Surfaces B: Biointerfaces, 28, 313-318. http://dx.doi.org/10.1016/S0927-7765(02)00174-1

[56] Duran, N., Marcato, P.D., Alves, O.L., De Souza, D.I.H. and Esposito, E. (2005) Mechanistic Aspect of Biosynthesis of Silver Nanoparticles by Several Fusarium oxysporum Species. Journal of Nanobiotechnology, 3, 8. http://dx.doi.org/10.1186/1477-3155-3-8

[57] Ingle, A., Rai, M., Gade, A. and Bawaskar, M. (2009) Fusarium solani: A Novel Biological Agent for the Extracellular Synthesis of Silver Nanoparticles. Journal of Nanoparticle Research, 11, 2079-2085. http://dx.doi.org/10.1007/s11051-008-9573-y

[58] Perni, S., Hakala, V. and Prokopovich, K. (2014) Biogenic Synthesis of Antimicrobial Silver Nanoparticles Caped with L-Cystine. Colloids and Surfaces A: Physicochemical and Engineering Aspects, 460, 219-224.

[59] Shahverdi, A.R., Minaeian, S., Shahverdi, H.R., Jamalifar, H. and Nohi, A.-A. (2007) Rapid Synthesis of Silver Nanoparticles Using Cultural Supernatants of Enterobacteria: A Novel Biological Approach. Process Biochemistry, 42, 919-923. http://dx.doi.org/10.1016/j.procbio.2007.02.005

[60] Ortega-Arroyo, L., Martin-Martinez, E.S., Aguilar-Mendez, M.A., Cruz-Orea, A., Hernandez-Perez, I. and Glorieux, C.(2013) Green Synthesis Method of Silver Nanoparticles Using Starch as Capping Agent Applied the Methodology of Surface Response. Starch/Starke, 65, 814-821. http://dx.doi.org/10.1002/star.201200255

[61] Morales-Sanchez, E., Guajardo-Pacheco, J., Noriega-Trevino, M., Quintero-Gonzalez, C., Compean-Jasso, M., LopezSalinas, F., Gonzalez-Hernandez, J. and Ruiz, F. (2011) Synthesis of Silver Nanoparticles Using Albumin as Reducing Agent. Materials Sciences and Applications, 2, 578-581. http://dx.doi.org/10.4236/msa.2011.26077

[62] Kora, A.J., Sashidhar, R.B. and Arunachalam, J. (2010) Gum Kondagogu (Cochlospermum gossypium): A Template for Green Synthesis and Stabilization of Silver Nanoparticles with Antibacterial Application. Carbohydrate Polymers, 82, 670-679. http://dx.doi.org/10.1016/j.carbpol.2010.05.034

[63] Sastry, M., Mayyaa, K.S. and Bandyopadhyay, K. (1997) pH Dependent Changes in the Optical Properties of Carboxylic Acid Derivatized Silver Colloid Particles. Colloids and Surfaces A: Physicochemical and Engineering Aspects, 127, 221-228. http://dx.doi.org/10.1016/S0927-7757(97)00087-3

[64] Jagtap, U.B. and Bapat, V.A. (2013) Green Synthesis of Silver Nanoparticles Using Artocarpus heterophyllus Lam. Seed Extract and Its Antibacterial Activity. Industrial Crops and Products, 46, 132-137. http://dx.doi.org/10.1016/j.indcrop.2013.01.019

[65] Vijayaraghavan, K., Nalini, S.P.K., Prakash, N.U. and Madhankumar, D. (2012) One Step Green Synthesis of Silver nano/Micro Particles Using Extracts of Trahyspermum ammi and Papaver somniferum. Colloids and Surfaces B: Biointerfaces, 94, 114-117. http://dx.doi.org/10.1016/j.colsurfb.2012.01.026

[66] Vigneswaran, N., Ashtaputre, N.M., Varadarajan, P.V., Nachane, R.P., Paralikar, K.M. and Balasubramanya, R.H. (2007) Biological Synthesis of Silver Nanoparticles Using the Fungus Aspergillus flavus. Materials Letters, 61, 14131418. http://dx.doi.org/10.1016/j.matlet.2006.07.042

[67] Vigneshwaran, N., Kathe, A.A., Varadarajan, P.V., Nachane, R.P. and Balasubramanya, R.H. (2006) Biomimitics of Silver Nanoparticles by White Rot Fungus. Colloids and Surfaces B: Biointerfaces, 53, 55-59. http://dx.doi.org/10.1016/j.colsurfb.2006.07.014

[68] Kaviya, S., Santhanalakshmi, J. and Viswanathan, B. (2012) Biosynthesis of Silver Nanoflakes by Crossandra infundibuliformis Leaf Extract. Materials Letters, 67, 64-66. http://dx.doi.org/10.1016/j.matlet.2011.09.023 
[69] Sreekanth, T.V.M., Nagajyothi, P.C. and Lee, K.D. (2012) Dioscorea Batatas Rhizome-Assisted Rapid Biogenic Synthesis of Silver and Gold Nanoparticles. Synthesis and Reactivity in Inorganic, Metal-Organic, and Nano-Metal Chemistry, 42, 567-572. http://dx.doi.org/10.1080/15533174.2011.613886

[70] Rajakumar, G. and Rahuman, A.A. (2011) Larvaidal Activity of Synthesized Silver Nanoparticles Using Eclipta prostrata Leaf Extract against Filariasis and Malaria Vectors. Acta Tropica, 118, 196-203. http://dx.doi.org/10.1016/j.actatropica.2011.03.003

[71] Sant, D.G., Gujarathi, T.R., Harne, S.R., Ghosh, S., Kitture, R., Kale, S., Chopade, B.A. and Pardesi, K.R. (2013) Adiantum phillipenseL. Frond Assisted Rapid Green Synthesis of Gold and Silver Nanoparticles. Journal of Nanoparticles, 2013, Article ID: 182320.

[72] Satishkumar, G., Gobinath, G., Karpagam, K., Hemamalini, V., Premkumar, K. and Sivaramakrishna, S. (2012) Phyto-Synthesis of Silver Nanoscale Particles Using Morinda citifolia L. and Its Inhibitory Action against Human Pathogens. Colloids and Surfaces B: Biointerfaces, 95, 235-240. http://dx.doi.org/10.1016/j.colsurfb.2012.03.001

[73] Jha, A.K., Prasad, K., Prasad, K. and Kulkarni, A.R. (2009) Plant System: Natures Nanofactory. Colloids and Surfaces B: Biointerfaces, 73, 219-223. http://dx.doi.org/10.1016/j.colsurfb.2009.05.018

[74] Yang, N. and Li, W.H. (2013) Mango Peel Extract Mediated Novel Route or Synthesis of Silver Nanoparticles and Antibacterial Application of Silver Nanoparticles Loaded onto Non-Woven Fibers. Industrial Crops and Products, 48, 81-88. http://dx.doi.org/10.1016/j.indcrop.2013.04.001

[75] Khalil, M.M.H., Ismail, E.H., El-Bhaghdady, K.Z. and Mohamed, D. (2014) Green Synthesis of Silver Nanoparticles Using Olive Leaf Extract and Its Antibacterial Activity. Arabian Journal of Chemistry, 7, 1131-1139.

[76] Das, S.K., Khan, M.M.R., Guha, A.K., Das, A.K. and Mandal, A.B. (2012) Silver-NanoBiohybrid Material: Synthesis, Characterization and Application in Water Purification. Bioresource Technology, 124, 495-499. http://dx.doi.org/10.1016/j.biortech.2012.08.071

[77] Ashraf, S., Abbasi, A.Z., Pfeiffer, C., Hussain, S.Z., Khalid, Z.M., Gil, P.R., Parak, W.J. and Hussain, I. (2013) Protein-Mediated Synthesis, pH-Induced Reversible Agglomeration, Toxicity and Cellular Interaction of Silver Nanoparticles. Colloids and Surfaces B: Biointerfaces, 102, 511-518. http://dx.doi.org/10.1016/j.colsurfb.2012.09.032

[78] Dehnavi, A.S., Raisi, A. and Aroujalian, A. (2013) Control Size and Stability of Colloidal Silver Nanoparticles with Antibacterial Activity Prepared by a Green Synthesis Method. Synthesis and Reactivity in Inorganic, Metal-Organic, and Nano-Metal Chemistry, 43, 543-551. http://dx.doi.org/10.1080/15533174.2012.741182

[79] Dubey, S.P., Lahtinen, M. and Sillianpaa, M. (2010) Tansy Fruit Mediated Greener Synthesis of Silver and Gold Nanoparticles. Process Biochemistry, 45, 1065-1071.http://dx.doi.org/10.1016/j.procbio.2010.03.024

[80] Tagad, C.K., Dugasani, S.R., Aiyer, R., Park, S., Kulkarni, A. and Sabharwal, S. (2013)Green Synthesis of Silver Nanoparticles and Their Application for the Development of Optical Fiber Based Hydrogen Peroxide Sensor. Sensors and Actuators B: Chemical, 183, 144-149. http://dx.doi.org/10.1016/j.snb.2013.03.106

[81] El-Rafie, M.H., El-Nagger, M.E., Ramadan, M.A., Fouda, M.M.G., Al Deyab, S.S. and Hebeish, A. (2011) Environmental Synthesis of Silver Nanoparticles Using Hydroxypropyl Starch and Their Characterization. Carbohydrate Polymers, 86, 630-635. http://dx.doi.org/10.1016/j.carbpol.2011.04.088

[82] Fayaz, A.M., Balaji, K., Kalaichelvan, P.T. and Venkatesan, R. (2009) Fungal Based Synthesis of Silver Nanoparticles-An Effect of Temperature on the Size of Particles. Colloids and Surfaces B: Biointerfaces, 74, 123-126. http://dx.doi.org/10.1016/j.colsurfb.2009.07.002

[83] Zonnoz, N.F. and Salouti, M. (2011) Extracellular Biosynthesis of Silver Nanoparticles Using Cell Filtrate of Streptomyces sp. ERI-3. Scientia Iranica, 18, 1631-1635. http://dx.doi.org/10.1016/j.scient.2011.11.029

[84] Kathiraven, T., Sundaramanickam, A., Shanmugam, N. and Balasubramanian, T. (2014) Green Synthesis of Silver Nanoparticles Using Marine Algae Caulerpa resmosa and Their Anti-Baterial Activity against Some Human Pathogens. Applied Nanoscience, 5, 499-504. http://dx.doi.org/10.1007/s13204-014-0341-2

[85] Vivek, M., Kumar, P.S., Steffi, S. and Sudha, S. (2011) Biogenic Silver Nanoparticles by Gelidiella acerosa Extract and Their Antifungal Effects. Avicenna Journal of Medical Biotechnology, 3, 143-148.

[86] Govindaraju, K., Kiruthiga, V., Kumar, V.G. and Singaravelu, G.(2009) Extracellular Synthesis of Silver Nanoparticles by Marine Algae, Sargassum wightii Grevilli and Their Antibacterial Effects. Journal of Nanoscience and Nanotechnology, 9, 5497-5501. http://dx.doi.org/10.1166/jnn.2009.1199

[87] Srivastava, A.A., Kulkarni, A.P., Harpale, P.M. and Zunjarrao, R.S. (2011) Plant Mediated Synthesis of Silver Nanoparticles Using a Bryophyte: Fissidens minutes and Its Anti-Microbial Activity. International Journal of Engineering Science and Technology, 3, 8342-8347.

[88] Kulkarni, A.P., Srivastava, A.A., Harpale, P.M. and Zunjarrao, R.S. (2011) Plant Mediated Synthesis of Silver Nanoparticles-Tapping the Unexploited Resources. Journal of Natural Product and Plant Resources, 1, 100-107.

[89] Britto, J.D., Gracelin, D.H.S. and Kumar, P.B.J.R. (2014) Antibacterial Activity of Silver Nanoparticles Synthesized 
from a Few Medicinal Ferns. International Journal of Pharmaceutical Research and Development, 6, 25-29.

[90] Bhor, G., Maskare, S., Hinge, S., Singh, L. and Nalwade, A. (2014) Synthesis of Silver Nanoparticles Using Leaflet Extract of Nephrolepi sexaltata L. and Evaluation Antibacterial Activity against Human and Plant Pathogenic Bacteria. Asian Journal of Pharmaceutical Technology and Innovation, 2.

[91] Nalwade, A.R., Badhe, M.N., Pawale, C.B. and Hinge, S.B. (2013) Rapid Biosynthesis of Silver Nanoparticles Using Fern Leaflet Extract and Evaluation of Their Antibacterial Activity. International Journal of Biological Technology, 4, 12-18.

[92] Kang, K.C., Kim, S.S., Baik, M.H., Choi, J.W. and Kwon, S.H. (2008) Synthesis of Silver Nanoparticles Using Green Chemical Method. Applied Chemistry, 12, 281-284.

[93] Jha, A.K. and Prasad, K. (2010) Green Synthesis of Silver Nanoparticles Using Cycas Leaf. International Journal of Green Nanotechnology: Physics and Chemistry, 1, 110-117. http://dx.doi.org/10.1080/19430871003684572

[94] Ashokkumar, S., Ravi, S., Kathiravan, V. and Velmurugan, S. (2015) Synthesis of Silver Nanoparticles Using A. indicum Leaf Extract and Their Antibacterial Activity. Spectrochimica Acta Part A: Molecular and Biomolecular Spectroscopy, 134, 34-39. http://dx.doi.org/10.1016/j.saa.2014.05.076

[95] Ajitha, A., Reddy, Y.A.K. and Reddy, P.S. (2014) Biogenic Nano-Scale Silver Particles by Tephrosia purpurea Leaf Extract and Their Inborn Antimicrobial Activity. Spectrochimica Acta Part A: Molecular and Biomolecular Spectroscopy, 121, 164-172. http://dx.doi.org/10.1016/j.saa.2013.10.077

[96] Suresh, P., Gunasekar, P.H., Kokila, D., Prabhu, D., Dinesh, D., Ravichandran, N., Ramesh, B., Koodalingam, A. and Siva, G.V.(2014) Green Synthesis of Silver Nanoparticles Using Delphinium denundatum Root Extract Exhibits Antibacterial and Mosquito Larvicidal Activities. Spectrochimica Acta Part A: Molecular and Biomolecular Spectroscopy, 127, 61-66. http://dx.doi.org/10.1016/j.saa.2014.02.030

[97] Zuas, O., Hamim, N. and Sampora, Y.(2014) Bio-Synthesis of Silver Nanoparticles Using Water Extract of Myrmecodia pendan (Sarang Semut Plant). Materials Letters, 123, 156-159. http://dx.doi.org/10.1016/j.matlet.2014.03.026

[98] Raut, R.W., Mendhulkar, V.D. and Kashid, S.B. (2014) Photosensitized Synthesis of Silver Nanoparticles Using Withania somnifera Leaf Powder and Silver Nitrate. Journal of Photochemistry and Photobiology B: Biology, 132, 45-55. http://dx.doi.org/10.1016/j.jphotobiol.2014.02.001

[99] Singh, P.K., Bhardwaj, K., Dubey, P. and Prabhune, A. (2015) UV-Assisted Size Sampling and Antibacterial Screening of Lantana camara Leaf Extract Synthesized Silver Nanoparticles. RSC Advances, 5, 24513-24520. http://dx.doi.org/10.1039/C4RA17233G

[100] Vimala, R.T.V., Satishkumar, G. and Sivramakrishnan, S. (2015) Optimization of Reaction Conditions to Fabricate Nano Silover Using Couroupita guianensis Aubel(Leaf \& Fruit) and Its Enhanced Larvicidal Effects. Spectrochimica Acta Part A: Molecular and Biomolecular Spectroscopy, 135, 110-115. http://dx.doi.org/10.1016/j.saa.2014.06.009

[101] Zhang, Y., Cheng, X., Zhang, Y., Xue, X. and Fu, Y.(2013) Biosynthesis of Silver Nanoparticles at Room Temperature Using Aqueous Aloe Leaf Extract and Antibacterial Properties. Colloids and Surfaces A: Physicochemical and Engineering Aspects, 423, 63-68. http://dx.doi.org/10.1016/j.colsurfa.2013.01.059

[102] Karuppiah, M. and Rajmohan, R. (2013) Green Synthesis of Silver Nanoparticles Using Ixora coccinea Leaves Extract. Materials Letters, 97, 141-143. http://dx.doi.org/10.1016/j.matlet.2013.01.087

[103] Logeswari, P., Silambarasan, S. and Abraham, J. (2013) Ecofriendly Synthesis of Silver Nanoparticles from Commercially Available Plant Powders and Their Antibacterial Properties. Scientia Iranica, 20, 1049-1054.

[104] Geethalakshmi, R. and Sarada, D.V.L.(2013) Characterization and Antimicrobial Activity of Gold and Silver Nanoparticles Synthesized Using Saponin Isolated from Trianthema decendra L. Industrial Crops and Products,51, 107-115. http://dx.doi.org/10.1016/j.indcrop.2013.08.055

[105] Yasin, S., Liu, L. and Yao, J. (2013) Biosynthesis of Silver Nanoparticles by Bamboo Leaves Extract and Their Antimicrobial Activity. Journal of Fiber Bioengineering and Informatics, 6, 77-84. http://dx.doi.org/10.3993/jfbi03201307

[106] Rodriguez, L.E., Iniguez, P.R., Navarro, R.E., Herrera, U.R., Tanori, J., Iniguez, P.C. and Maldonado, A. (2013) Synthesis of Silver Nanoparticles Using Reducing Agents Obtained from Natural Sources (Rumex hymenosepalus Extracts).Nanoscale Research Letters, 8, 318. http://dx.doi.org/10.1186/1556-276X-8-318

[107] Rajathi, K. and Sridhar, S. (2013) Green Synthesis of Silver Nanoparticles from the Medicinal Plant Wrightia tinctoria and Its Antimicrobial Potential. International Journal of ChemTech Research, 5, 1701-1713.

[108] Kannan, R.R.R., Strik, W.A. and Staden, V. (2013) Synthesis of Silver Nanoparticles Using the Seaweed Codium capitatum P.C. Silva (Chlorophyceae). South African Journal of Botany, 86, 1-4. http://dx.doi.org/10.1016/j.sajb.2013.01.003

[109] Natarajan, R.K., John Nayagam, A.A., Gurunagarajan, S., Muthukumar, Ekambaram, N. and Manimaran, A. (2013) Elaeagnus indica Mediated Green Synthesis of Silver Nanoparticles and Its Potent Toxicity against Human Pathogens. 
Global Journal of Pharmacology, 7, 222-231.

[110] Kirubaharan, C.J., Kalpana, D., Lee, Y.S., Kim, A.R., Yoo, D.J., Nahm, K.S. and Kumar, G.G.(2012) Biomediated Silver Nanoparticles for the Highly Selective Copper(II) Ion Sensor Applications. Industrial and Engineering Chemistry Research, 51, 7441-7446. http://dx.doi.org/10.1021/ie3003232

[111] Gopinath, V., Mubarakali, D., Priyadarshini, S., Priyadharsshini, N.M., Thajuddin, N. and Velusamy, P. (2012) Biosynthesis of Silver Nanoparticles from Tribulus terrestris and Its Antimicrobial Activity: A Novel Biological Approach. Colloids and Surfaces B: Biointerfaces, 96, 69-74. http://dx.doi.org/10.1016/j.colsurfb.2012.03.023

[112] Chaudhary, S., Paul, S. and Sagar, S. (2012) Biosynthesis of Silver Nanoparticles Using Vitis vinifera Extract and Evaluation of Their Antimicrobial Activity. International Journal of Bio-Technology and Research, 2, 1-12.

[113] Ashok Kumar, D. (2012) Rapid and Green Synthesis of Silver Nanoparticles Using the Leaf Extracts of Parthenium hysterophorus: A Novel Biological Approach. International Research Journal of Pharmacy, 3, 169-173.

[114] Arunachalam, K.D., Annamalai, S.K., Arunachalam, A.M. and Kennedy, S. (2013) Green Synthesis of Crystalline Silver Nanoparticles Using Indigofera Aspalathoides-Medicinal Plant Extract for Wound Healing Applications. Asian Journal of Chemistry, 25, S311-S314.

[115] Mubarakali, D., Thajuddin, N., Jeganathan, K. and Gunasekaran, M. (2011) Plant Extract Mediated Synthesis of Silver and Gold Nanoparticles and Its Antibacterial Activity against Clinically Isolated Pathogens. Colloids and Surfaces B: Biointerfaces, 85, 360-365. http://dx.doi.org/10.1016/j.colsurfb.2011.03.009

[116] Kumar, V. and Yadav, S.K. (2011) Synthesis of Stable, Polyshaped Silver and Gold Nanoparticles Using Leaf Extract of Lonicera japonica L. International Journal of Green Nanotechnology, 3, 281-291. http://dx.doi.org/10.1080/19430892.2011.633474

[117] Gnanadesigan, M., Anand, M., Ravikumar, S., Maruthupandy, M., Vijaykumar, V., Selvam, S., et al. (2011) Biosynthesis of Silver Nanoparticles Using Mangrove Plant Extract and Their Potential Mosquito Larvicidal Property. Asian Pacific Journal of Tropical Disease, 4, 799-803. http://dx.doi.org/10.1016/S1995-7645(11)60197-1

[118] Rani, P.U. and Rajasekharreddy, P.(2011) Green Synthesis of Silver-Protein (Core-Shell) Nanoparticles Using Piper betel L. Leaf Extract and Its Ecotoxicological Studies on Daphnia manga.Colloids and Surfaces A: Physicochemical and Engineering Aspects, 389, 188-194. http://dx.doi.org/10.1016/j.colsurfa.2011.08.028

[119] Veerasamy, R., Xin, T.Z., Gunasagaran, S., Xiang, T.F.W., Yang, E.F.C., Jeyakumar, N. and Dhanaraj, S.A. (2011) Biosynthesis Silver Nanoparticles Using Mangosteen Leaf Extract and Evaluation of Their Antimicrobial Activities. Journal of Saudi Chemical Society, 15, 113-120. http://dx.doi.org/10.1016/j.jscs.2010.06.004

[120] Santoshkumar, T., Rahuman, A.A., Rajakumar, G., Marimuthu, S., Bagavan, A., Jayaseelan, C., Zahir, A.A., Elango, G. and Kamaraj, C. (2011) Synthesis of Silver Nanoparticles Using Nelumbo nucifera Leaf Extract and Its Larvicidal Activity against Malaria and Filariasis Vectors.Parasitology Research, 108, 693-702. http://dx.doi.org/10.1007/s00436-010-2115-4

[121] Ahmad, N., Sharma, S., Singh, V.N., Shamsi, S.F., Fatma, A. and Mehta, B.R. (2011) Biosynthesis of Silver Nanoparticles from Desmodium triflorum: A Novel Approach towards Weed Utilization. Biotechnology Research International, 2011, Article ID: 454090. http://dx.doi.org/10.4061/2011/454090

[122] Prathna, T.C., Chandrasekaran, N., Raichur, A.M. and Mukherjee, A. (2011) Biomimetic Synthesis of Silver Nanoparticles by Citrus limon (Lemon) Aqueous Extract and Theoretical Prediction of Particle Size. Colloids and Surfaces B: Biointerfaces, 82, 152-159. http://dx.doi.org/10.1016/j.colsurfb.2010.08.036

[123] Njagi, E.C., Huang, H., Stafford, L., Genuino, H., Galindo, H.M., Collins, J.B., Hoag, G.E. and Suib, S.L. (2011) Biosynthesis of Iron and Silver Nanoaparticles at Room Temperature Using Aqueous Sorghum Bran Extracts. Langmuir, 27, 264-271. http://dx.doi.org/10.1021/la103190n

[124] Kumar, V., Yadav, S.C. and Yadav, S.K. (2010) Syzygium cumini Leaf Extract and Seed Extract Mediated Biosynthesis of Silver Nanoparticles and Their Characterization. Journal of Chemical Technology and Biotechnology, 85, 1301-1309. http://dx.doi.org/10.1002/jctb.2427

[125] Krishnaraj, C., Jagan, E.G., Rajasekar, S., Selvakumar, P., Kalaichelvan, P.T. and Mohan, N. (2010) Synthesis of Silver Nanoparticles Using Aclypha indica Extracts and Its Antibacterial Activity against Water Borne Pathogens. Colloids and Surfaces B: Biointerfaces, 76, 50-56.http://dx.doi.org/10.1016/j.colsurfb.2009.10.008

[126] Leela, A. and Vivekanandan, M. (2008) Tapping the Unexploited Plant Resources for the Synthesis of Silver Nanoparticles. African Journal of Biotechnology, 7, 31662-3165.

[127] Shankar, S.S., Rai, A., Ahmad, A. and Sastry, M. (2004) Rapid Synthesis of Au, Ag and Bimetallic Au Core-Ag Shell Nanoparticles Using Neem (Azadirachta indica) Leaf Broth. Journal of Colloid and Interface Science, 275, 496-502. http://dx.doi.org/10.1016/j.jcis.2004.03.003

[128] Naveen, K.S.H., Kumar, G., Karthik, L. and Rao, K.V.B. (2010) Extracellular Biosynthesis of Silver Nanoparticles Using the Filamentous Fungus Penicillium sp. Archives of Applied Science Research, 2, 161-167. 
[129] Balaji, D.S., Basavaraja, S., Deshpande, R., Mahesh, D.B., Prabhakar, B.K. and Venkataraman, A. (2009) Extracellular Biosynthesis of Functionalized Silver Nanoparticles by Strains of Cladosporium cladosporioides Fungus. Colloids and Surfaces B: Biointerfaces, 68, 88-92. http://dx.doi.org/10.1016/j.colsurfb.2008.09.022

[130] Shaligram, N.S., Bule, M., Bhambure, R., Singhal, R.S., Singh, S.K., Szakacs, G. and Pandey, A. (2009) Biosynthesis of Silver Nanoparticles Using Aqueous Extract from the Compactin Producing Fungal Strain. Process Biochemistry, 44, 939-943. http://dx.doi.org/10.1016/j.procbio.2009.04.009

[131] Kathiresan, K., Manivannan, S., Nabeel, M.A. and Dhivya, B. (2009) Studies on Silver Nanoparticles Synthesized by Marine Fungus, Penicillium fellutanum Isolated from Coastal Mangrove Sediment. Colloids and Surfaces B: Biointerfaces, 71, 133-137. http://dx.doi.org/10.1016/j.colsurfb.2009.01.016

[132] Basavaraja, S., Balaji, S.D., Lagashetty, A., Rajasab, A.H. and Venkataraman, A. (2008) Extracellular Biosynthesis of Silver Nanoparticles Using the Fungus Fusarium semitectum. Materials Research Bulletin, 43, 1164-1170. http://dx.doi.org/10.1016/j.materresbull.2007.06.020

[133] Senapati, S., Mandal, D., Ahmad, A., Khan, M.I., Sastry, M. and Kumar, R. (2004) Fungus Mediated Synthesis of Silver Nanoparticles: A Novel Biological Approach. Indian Journal of Physics, 78, 101-105.

[134] Zhang, M., Zhang, K., Gusseme, B.D., Verstraete, W. and Field, R. (2014) The Antibacterial and Anti-Biofouling Performance of Biogenic Silver Nanoparticles by Lactobacillus fermentum. Biofouling: The Journal of Bioadhesion and Biofilm Research, 30, 347-357.http://dx.doi.org/10.1080/08927014.2013.873419

[135] Deepak, V., Umamaheshwaran, P.S., Guhan, K., Nanthini, R.A., Krithiga, B., Jaithoon, N.M.H. and Gurunathan, S. (2011) Synthesis of Gold and Silver Nanoparticles Using Purified URAK. Colloids and Surfaces B: Biointerfaces, 86, 353-358.http://dx.doi.org/10.1016/j.colsurfb.2011.04.019

[136] Kalishwaralal, K., Deepak, V., Pandian, S.R.K., Kottaisamy, M., Barathmanikanth, S., Kartikeyan, B. and Gurunathan, S. (2010) Biosynthesis of Silver and Gold Nanoparticles Using Brevibacterium casei. Colloids and Surfaces B: Biointerfaces, 77, 257-262. http://dx.doi.org/10.1016/j.colsurfb.2010.02.007

[137] Babu, M.M.G. and Gunasekaran, P. (2009) Production and Structural Characterization of Crystalline Silver Nanoparticles from Bacillus cereus Isolate. Colloids and Surfaces B: Biointerfaces, 74, 191-195. http://dx.doi.org/10.1016/j.colsurfb.2009.07.016

[138] Nanda, A. and Saravanan, M. (2009) Biosynthesis of Silver Nanoparticles from Staphylococcus aureus and Its Antimicrobial Activity against MRSA and MRSE. Nanomedicine: Nanotechnology, Biology and Medicine, 5, 452-456. http://dx.doi.org/10.1016/j.nano.2009.01.012

[139] Kalimuthu, K., Babu, R.S., Venkataraman, D., Bilal, M. and Gurunathan, S. (2008) Biosynthesis of Silver Nanocrystals by Bacillus licheniformis. Colloids and Surfaces B: Biointerfaces, 65, 150-153. http://dx.doi.org/10.1016/j.colsurfb.2008.02.018

[140] Juibari, M.M., Abbasalizadeh, S., Jouzani, G.S. and Noruzi, M. (2011) Intensified Biosynthesis of Silver Nanoparticles Using a Native Extremophilic Ureibacillus thermosphaerius Strain. Materials Letters, 65, 1014-1017. http://dx.doi.org/10.1016/j.matlet.2010.12.056

[141] Gurunathan, S., Kalishwaralal, K., Vaidhyanathan, R., Deepak, V., Pandian, S.R.K., Muniyandi, J., Hariharan, N. and Eom, S.H.(2009) Biosynthesis, Purification and Characterization of Silver Nanoparticles Using Escherichia coli. Colloids and Surfaces B: Biointerfaces, 74, 328-335. http://dx.doi.org/10.1016/j.colsurfb.2009.07.048

[142] Cheng, K.M., Hung, Y.W., Chen, C.C., Lin, C.C. and Yong, J.J. (2014) Green Synthesis of Chondroitin SulfateCapped Silver Nanoparticles: Characterization and Surface Modification. Carbohydrate Polymers, 110, $195-202$. http://dx.doi.org/10.1016/j.carbpol.2014.03.053

[143] Chen, Q., Jiang, H., Ye, H., Li, J. and Huang, J. (2014) Preparation, Antibacterial, and Antioxidant Activities of Silver/Chitosan Composities. Journal of Carbohydrate Chemistry, 33, 298-312.

[144] El-Rafie, H.M., El-Rafie, M.H. and Zahran, M.K. (2013) Green Synthesis of Silver Nanoparticles Using Polysaccharides Extracted from Marine Macro Algae. Carbohydrate Polymers, 96, 403-410. http://dx.doi.org/10.1016/j.carbpol.2013.03.071

[145] Lu, R., Yang, D., Cui, D., Wang, Z. and Guo, L. (2012) Egg White-Mediated Green Synthesis of Silver Nanoparticles with Excellent Biocompatibility and Enhanced Radiation Effects on Cancer Cells. International Journal of Nanomedicine, 7, 2101-2107. http://dx.doi.org/10.2147/IJN.S29762

[146] Guidelli, E.D., Ramos, A.P., Zaniquelli, M.E.D., Nicolucci, P. and Baffa, O. (2012) Synthesis of Silver Nanoparticles Using DL-Alanine for ESR Dosimetry Applications. Radiation Physics and Chemistry, 81, 301-307. http://dx.doi.org/10.1016/j.radphyschem.2011.10.020

[147] Tanvir, S., Oudet, F., Pulvin, S. and Anderson, W.A.(2012) Coenzyme Based Synthesis of Silver Nanorystals. Enzyme and Microbial Technology, 51, 231-236. http://dx.doi.org/10.1016/j.enzmictec.2012.07.002

[148] Bankura, K.P., Maity, D., Mollick, M.M.R., Mondal, D., Bhowmick, B., Bain, M.K., Chakraborty, A., Sarkar, J., 
Acharya, K. and Chattopadhyay, D. (2012) Synthesis, Characterization and Antimicrobial Activity of Dextran Stabilized Silver Nanoparticles in Aqueous Medium. Carbohydrate Polymers, 89, 1159-1165. http://dx.doi.org/10.1016/j.carbpol.2012.03.089

[149] Sasikala, D., Govindaraju, K., Tamilselvan, K. and Singaravelu, G. (2012) Soyabean Protein: A Natural Source for the Production of Green Silver Nanoparticles. Biotechnology and Bioprocess Engineering, 17, 1176-1181. http://dx.doi.org/10.1007/s12257-012-0021-6

[150] Kim, K.J., Sung, W.S., Suh, B.K., Moon, S.K., Choi, J.S., Kim, J.G. and Lee, D.G. (2009) Antifungal Activity and Mode of Action of Silver Nanoparticles on Candida albicans. Biometals, 22, 235-242. http://dx.doi.org/10.1007/s10534-008-9159-2

[151] Rai, M.K., Deshmukh, S.D., Ingle, A.P. and Gade, A.K. (2012) Silver Nanoparticles: The Powerful Nanoweapon against Multidrug-Resistant Bacteria. Journal of Applied Microbiology, 112, 841-852. http://dx.doi.org/10.1111/j.1365-2672.2012.05253.x

[152] Marimuthu, S., Rahuman, A.A., Rajakumar, G., Santhoshkumar, T., Kirthi, A.V., Jayaseelan, C., Bagavan, A., Zahir, A.A., Elango, G. and Kamaraj, C. (2011) Evaluation of Green Synthesized Silver Nanoparticles against Parasites. Parasitology Research, 108, 1541-1549. http://dx.doi.org/10.1007/s00436-010-2212-4

[153] Tran, Q.H., Nguyen, V.Q. and Le, A.T. (2013) Silver Nanoparticles: Synthesis, Properties, Toxicology, Applications and Perspectives. Advances in Natural Sciences: Nanoscience and Nanotechnology, 4, Article ID: 033001. http://dx.doi.org/10.1088/2043-6262/4/3/033001 